\title{
Geophysical Surveys for Buried Waste Detection at the Idaho National Engineering Laboratory
}

\author{
G. A. Sandness \\ J. L. Rising \\ J. R. Kimbrough
}

December 1979

Prepared for EG\&G Idaho Incorporated under a Related Services Agreement with the U. S. Department of Energy

Contract EY-76-C-06-1830

Pacific Northwest Laboratory Operated for the U.S. Department of Energy by Battelle Memorial Institute 


\title{
NOTICE
}

This report was prepared as an account of work sponsored by the United States Government. Neither the United States nor the Department of Energy, nor any of their employees, nor any of their contractors, subcontractors, or their employees, makes any warranty, express or implied, or assumes any legal liability or responsibility for the accuracy, completeness or usefulness of any information, apparatus, product or process disclosed, or represents that its use would not infringe privately owned rights.

The views, opinions and conclusions contained in this report are those of the contractor and do not necessarily represent those of the United States Government or the United States Department of Energy.

\author{
PACIFIC NORTHWEST LABORATORY \\ operated by \\ BATTELLE \\ for the \\ UNITED STATES DEPARTMENT OF ENERGY \\ Under Contract EY-76-C-06-1830
}
Printed in the United States of America Available from
National Technical Information Service
United States Department of Commerce 5285 Port Royal Road
Springfield, Virginia 22151

Price: Printed Copy 5 . :) Microfiche $\$ 300$

$\begin{array}{cc}\text {-Pages } & \begin{array}{c}\text { NTIS } \\ \text { Selling Price }\end{array} \\ 001-025 & 54.00 \\ 025-050 & \$ 4.50 \\ 051-075 & 55.25 \\ 076-100 & 56.00 \\ 101-125 & \$ 6.30 \\ 126-150 & \$ 7.25 \\ 151-175 & 56.00 \\ 176-200 & 59.00 \\ 201-225 & 59.25 \\ 226-250 & 59.50 \\ 251-205 & 510.75 \\ 276-300 & 511.00\end{array}$


PNL-3227

UC-70

33679000544298

GEOPHYSICAL SURVEYS FOR BURIED

WASTE DETECTION AT THE IDAHO

NATIONAL ENGINEERING LABORATORY

G. A. Sandness

J. L. Rising

J. R. Kimbrough

December 1979

Prepared for EG\&G Idaho, Incorporated under a Related Services Agreement with the U.S. Department of Energy Contract EY-76-C-06-1830

Pacific Northwest Laboratory 


\section{ABSTRACT}

This report describes a series of geophysical surveys performed at the Idaho National Engineering Laboratory (INEL). The main purpose of the surveys was to evaluate techniques, principally ground-penetrating radar, for detecting and mapping radioactive wastes buried in shallow trenches and pits. A second purpose was to determine the feasibility of using ground-penetrating radar to measure the depth of basalt bedrock. A prototype geophysical survey system developed by the U.S. Department of Energy's Pacific Northwest Laboratory was used for this study. Radar, magnetometer, and metal detector measurements were made at three sites in the Radioactive Waste Management Complex (RWMC) at INEL. Radar measurements were made at a fourth site adjacent to the RWMC. The combination of three geophysical methods was shown to provide considerable information about the distribution of buried waste materials. The tests confirmed the potential effectiveness of the radar method, but they also pointed out the need for continued research and development in ground-penetrating radar technology. The radar system tested in this study appears to be capable of measuring the depth to basalt in the vicinity of the RWMC. 


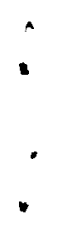




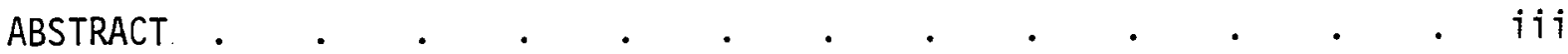

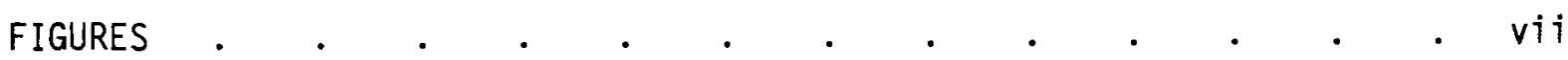

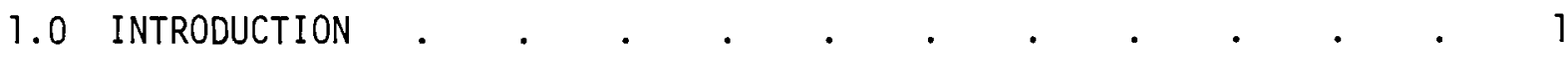

1.1 BACKGROUND $\quad . \quad$. $\quad . \quad$. $\quad . \quad$.

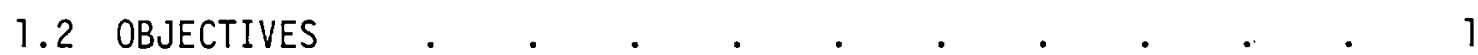

1.3 BASIC APPROACH . $. \quad . \quad . \quad . \quad . \quad . \quad . \quad . \quad . \quad . \quad . \quad . \quad 1$

2.0 SUMMARY, CONCLUSIONS AND RECOMMENDATIONS . . . . . . . . 3

2.1 WASTE DETECTION . . . . . . . . . . . . . 3

2.1 .1 Summary . . . . . . . . . . . . . . 3

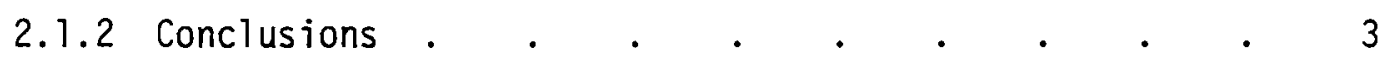

2.1.3 Recommendations . . . . . . . . . . . . 5

2.2 MEASUREMENT OF BASALT DEPTH . . . . . . . . . . 7

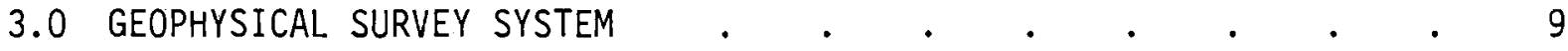

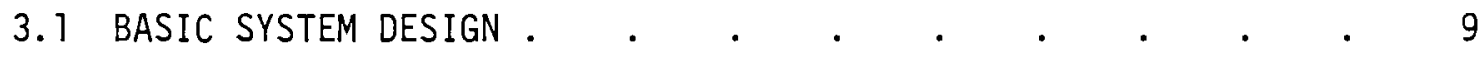

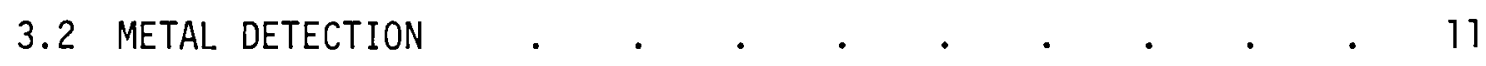

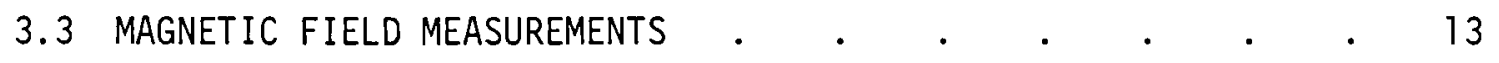

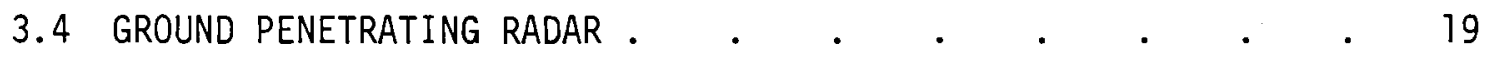

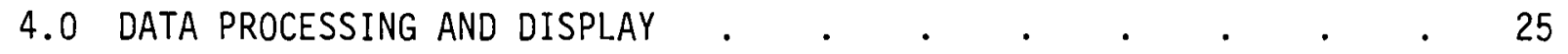

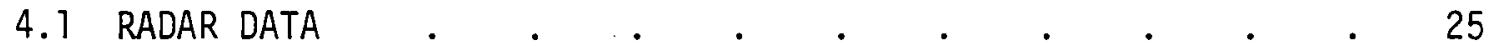

4.1 .1 Program REMVH $. \quad . \quad . \quad . \quad . \quad . \quad . \quad . \quad$. 26

4.1 .2 Program HYPER . . . . . . . . . . 27

4.1.3 Program SLICE $\quad . \quad$. $\quad . \quad$. $\quad . \quad$. $\quad . \quad$. 31

4.1.4 Program IDAPIC . . . . . . . . . . 32

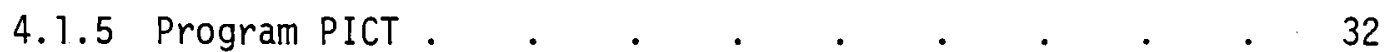

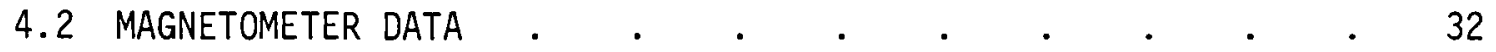

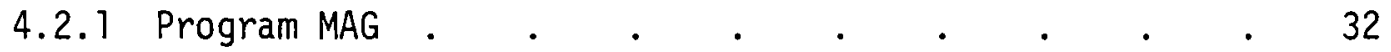

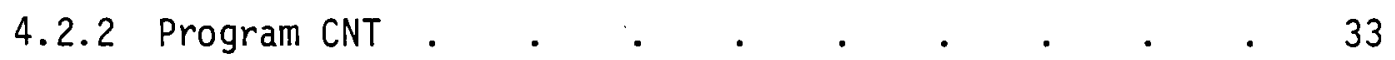

4.2.3 Program MAGP . . . . . . . . . . . 34

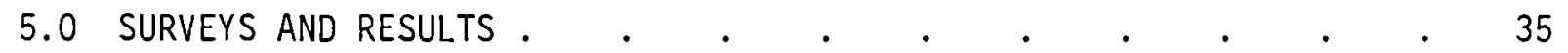

5. 1 INITIAL ACTIONS AND SITE PREPARATION $\quad . \quad$. $\quad . \quad$. $\quad 35$ 
5.2 DATA PROCESSING AND RADAR CALIBRATION . . . . . . $\quad$. 35

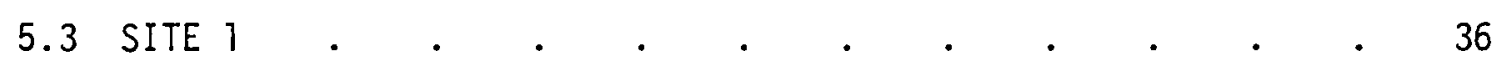

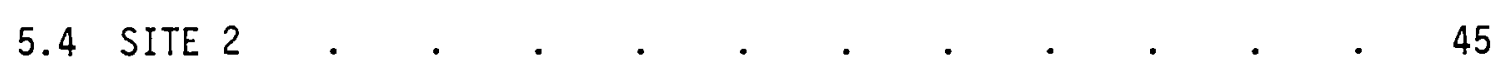

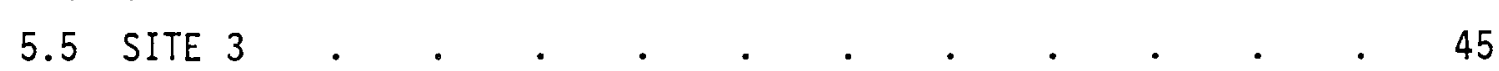

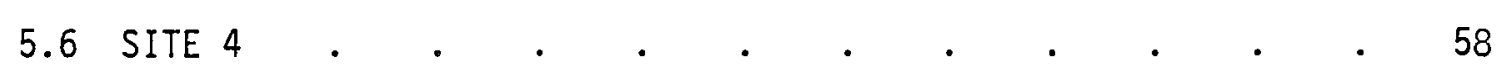

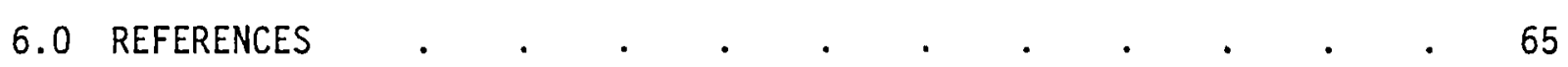




\section{FIGURES}

1 Survey Instruments Used in Burial Ground Surveys . . . . . 10

2 a) The Geophysical Survey Vehicle. The Radar Antenna is

Mounted on the Front of the Vehicle b) The Truck-Mounted

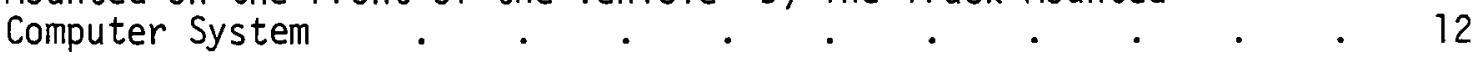

3 Map Showing the Intensity of the Earth's Magnetic Field.$\quad$. 15

4 Map Showing the Inclination of the Earth's Magnetic Field . . 16

5 Calculated Magnetic Field Anomaly Due to a Thin-Walled

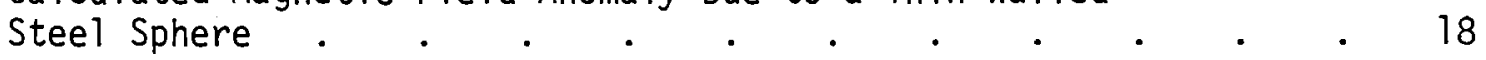

6 The Relative Dielectric Constant of Typical Soils for

Mo isture Content in the Range $0-20 \%$ by Weight . . . . 21

7 Measured Values of Radar Signal Absorption Loss Versus

Transmitted Frequency for Several Values of Moisture

Content

8 a) The Waveform Transmitted by the GSSI Radar

b) The Power Spectrum of the Signal Shown in a) . . . . 23

9 Computer Program Flow Chart for Radar and Magnetometer

Data.

10 Three Forms of One Radar Profile Illustrating Computer

Processing Operations

11 Reflection Geometry for Ground-Penetrating Radar

Profiling and the Occurrence of Hyperbolic Reflection

Patterns

12 Radar Ping Reflected from the Computer Truck . . . .

13 Diagram of Site 1 Showing Metal Detector Survey

Results

14 Diagram of Site 1 Showing Metal Detector and Magnetometer

Survey Results.

15 Level Sliced Color Map of Magnetic Data at Site 1 . . . . . 41

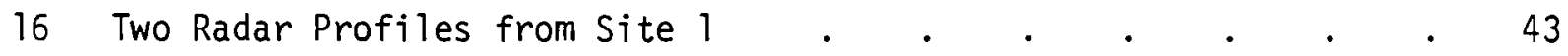

17 Level Sliced Color Map View of Radar Data from Site 1 . . . 44

18 Diagram of Site 2 Showing Metal Detector Survey Results . . 46 
19 Diagram of Site 2 Showing Metal Detector and Magnetometer Survey Results. . . . . . . . . . . 47

20 Level Sliced Color Map of Magnetic Data at Site 2. . . . 48

21 Two Radar Profiles from Site 2 . $\quad$. $\quad . \quad$. . . . . 49

22 Level Sliced Color Map View of Radar Data from Site 2 . . 50

23 Diagram of Site 3 .

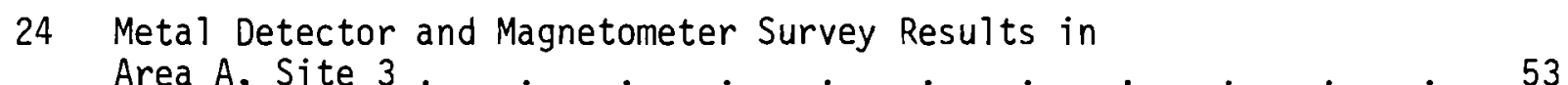

25 Level Sliced Color Map of Magnetic Data in
Area A, Site 3. . . . . . . 54

26 Two Radar Profiles from Area A, Site 3 . . . . . . 55

27 Level Sliced Color Map View of Radar Data from

28 Level Sliced Color Map of Magnetic Data in Area B, Site 3. . . . . . . . . . . 57

29 Two Radar Profiles from Area B, Site 3 . . . . . 59

30 Level Sliced Color Map View of Radar Data from . . . . . . 60

31 Test Site Location for Detection of Basalt Bedrock . . . 61

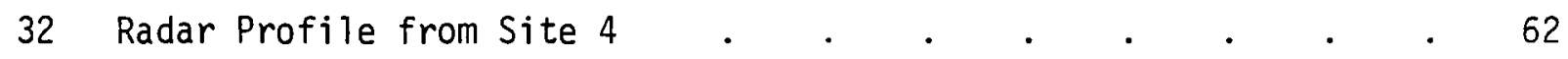

33 Two Radar Pings from the Basalt Detection Test Site . . . 63 


\subsection{INTRODUCTION}

\subsection{BACKGROUND}

During the period from 1954 to 1970, a large volume of radioactive waste material was buried in shallow trenches and pits at the Idaho National Engineering Laboratory (INEL). EG\&G Idaho, Inc., is currently examining several possible methods for managing this waste material. One of the methods under consideration involves retrieval, treatment, and transport of the materials to another repository. However, in order to implement this approach, it will be necessary to map the buried waste materials and to accurately determine the boundaries of the existing pits and trenches.

Methods for detecting and mapping buried waste materials have been recently studied at INEL. $(1,2)$ During the past several years, we have conducted similar studies at the U.S. Department of Energy's Pacific Northwest Laboratory (PNL) in Richland, Washington. As part of that work, we developed and tested a prototype geophysical system for burial ground surveys at the Hanford site in Washington. (3)

\subsection{OBJECTIVES}

The first objective of the work described in this report was to test the PNL system at the INEL site, specifically at the Radioactive Waste Management Complex (RWMC). The principal focus of this work was to evaluate the effectiveness of ground penetrating radar for detecting and mapping buried waste materials in the RWMC trenches.

The second objective was to determine the feasibility of using the radar unit to measure the depth to the basalt bedrock in the RWMC area.

\subsection{BASIC APPROACH}

We conducted test surveys at three sites within the RWMC. These tests were directed at evaluating the effectiveness of our geophysical system for detecting buried waste materials. One of these sites had been previously used for radar tests by EG\&G and was located over a filled trench containing 
known reflecting objects. The other two sites were located over filled burial trenches containing unknown waste materials. At each of these sites, we made metal detector and magnetometer measurements in addition to radar measurements.

The test site for measuring depth to basalt was located outside the RWMC fence near an existing observation well. At that site, we made magnetic measurements to complement the radar data.

We used a digital computer facility at PNL to process the radar and magnetic data and to produce hard copy output products. 


\subsection{SUMMARY, CONCLUSIONS AND RECOMMENDATIONS}

\subsection{WASTE DETECTION}

\section{1 .1 Summary}

Our metal detector and magnetometer data indicated the presence of one or more trenches containing buried metallic waste materials at each of the three sites within the RWMC. At Site 1 (see Section 5.3), the data show an apparent trench boundary under the road paralleling Trench 58. At Site 2 (see Section 5.4), they show 1 inear east-west distributions of metallic material that probably correspond to Trenches 5, 7 and 9. At Site 3 (see Section 5.5), they show 1 inear east-west waste distributions that are consistent with the pattern expected on the basis of information given to us by EG\&G.

The metal detector and magnetometer measurements provided a substantial amount of information regarding the locations of trenches and the composition of materials in them. But because they cannot normally detect non-metallic wastes, they did not definitively locate the trench boundaries.

At each of the three sites, the radar data supported or extended results of the metal detector and magnetometer measurements. At Site 1, the radar data clearly show the large metallic mass under the adjacent road, but could not unambiguously define test objects previously buried by EG\&G. At site 2, the radar data indicate the presence of waste materials that were not detected by the other measurements. At Site 3, the radar data are consistent with the results of the metal detector and magnetometer surveys. They also exhibit distinctive characteristics which may be diagnostic of certain types of waste materials or other subsurface reflectors. Additional data are needed to evaluate those signal responses.

\subsubsection{Conclusions}

In general, we found the radar profiles to be complex and difficult to interpret. It is probable that they contained much more information than we were able to extract from them.

Several factors may have contributed to the complexity of the radar data obtained in this study. These include: 
1) The burial trenches of the RWMC are closely spaced and most of the ground at our test sites has been disturbed by excavation. Consequently, reflections from buried wastes are not easily distinguished among numerous reflections from trench edges and soil inhomogeneities.

2) Ground surface roughness produces variations in signal character and travel time. In radar profiles, these variations have the appearance of a reflection pattern produced by an object buried just below the ground surface.

3) Unwanted subsurface reflections can be produced by a clay cap or other surface soil layer over a trench if the dielectric constant of the surface layer differs significantly from that of the underlying soil. If the bottom surface of such a layer is uneven, the resulting reflections can mask, or be confused with, reflections from deeper waste materials.

4) Oscillations, or ringing, lengthen the transmitted signal causing reflections from different depths to overlap.

5) The wide angular breadth of the transmitted radar beam yields complex reflections in areas where the number of reflecting objects is large, However, a wide beamwidth can facilitate target recognition if the number of reflectors is small.

6) If the radar signal is strongly reflected by a shallow subsurface interface, reflections from deeper objects or interfaces will be weak and may be completely masked by ringing in the upper reflection. If the upper reflector is metallic (the extreme case), no reflections will be received from deeper objects or reflective interfaces.

The scope of this brief study did not allow collection of the detailed ground truth data needed to fully evaluate observed radar signal characteristics. Additional ground truth data would probably make it possible to derive substantially more information from the radar data than we were able to derive in this project. Nevertheless, our conclusion is that an improved radar system, used in combination with other geophysical methods, will be required to accurately detect and map buried waste materials in the RWMC. 


\subsubsection{Recommendations}

A research and development program should be conducted to develop improved geophysical instrumentation and analys is techniques for waste detection and mapping. Improved burial ground survey systems are needed not only for DOE waste management activities at INEL and Hanford, but also for a broad spectrum of similar activities at many other radioactive and chemical waste disposal sites throughout the country. Recent efforts at PNL and INEL have been significant initial steps toward the development of an effective waste mapping capability, but continued progress will require a substantial future commitment of funds and a sustained and dedicated R\&D program.

In the following paragraphs, we briefly discuss four general technological areas in which we believe significant advances may be gained by further research and development efforts.

Radar Instrumentation - Ground penetrating radar technology is still in its infancy. Improvements should be possible in many aspects of system design. We suggest the following approaches:

- Improve antenna/transceiver design to reduce ringing, clutter, and electronic noise. Reductions of these noise factors will allow improved signal recognition and interpretation and will extend the effective penetration depth of the radar signals.

- Implement digital control of radar parameters, including timing, gain, and time varying gain settings.

- Utilize a microcomputer to optimize and control radar sampling rates and sampling intervals to maximize signal averaging and noise concellation. The purpose of this action is to increase the data acquisition rate and the signal-to-noise ratio.

- Study multiple antenna configurations. This approach would increase the data volume, and provide data redundancy. Coupled with digital data processing, it may help to identify reflective objects and to determine the ir Tocations. 
- Investigate the applicability of a continuous wave, or chirped, radar system.

- Perform intensive system tests under controlled conditions.

Radar Data Analysis - We consider digital methods of acquiring, storing, and processing burial ground survey data to be more efficient and flexible than analog methods. We believe, therefore, that digital methods should be a basic element in the design of a geophysical survey system to be used for operational surveys of large burial sites. Further, the analysis of radar, magnetic, and other potentially applicable types of geophysical data is greatly facilitated by the use of a digital computer. Digital methods appear to offer the best means for extracting information from complex data such as groundpenetrating radar outputs. We have stressed the digital approach in our work at PNL and have made substantial progress. The following tasks would yield other important advancements:

- Implement an improved real-time data processing and display capability utilizing a color graphics display device. This would provide a means for field personnel to monitor and evaluate incoming data and to optimize their data collection procedures.

- Develop improved computer software for radar data analysis. This would include a deconvolution program to remove the oscillating transmitted waveform from the received signals.

- Develop an interactive computer graphics technique for modeling the three-demensional distribution of ferromagnetic waste materials in a trench. The model would be based on measured magnetic data, but would be refined by the application of geometric constraints derived from metal detector and radar data, trench depth limitations, and other available information.

Radar Signal Propagation and Scattering - Physical measurements and general theoretical or computational studies are needed to optimize radar system design and to better understand and interpret radar reflection data. The following tasks would be useful: 
- Measure the dielectric constant, moisture content, density, composition, magnetic susceptibility, and electrical conductivity of the soil at the RWMC. Determine the horizontal and vertical variability of those factors.

- Study the effects of the above factors and their variations on the propagation and scattering of radar signals. Evaluate the frequency or wavelength dependence of those effects.

- Study the reflection or scattering characteristics of rough surfaces and three-dimensional objects.

Survey Methods Other Than Radar - Because a radar system has the potential to detect both metallic and non-metallic materials, it must be considered to be the most important available tool for burial ground mapping applications. But other geophysical instruments, such as metal detectors and magnetometers, are also important as supplementary tools. At the present stage of radar development, they are often more effective than radar in locating buried wastes. The following tasks would be useful:

- Develop an improved metal detector. An instrument should be designed specifically for waste detection and should provide deep penetration together with improved sensitivity, resolution, and noise rejection. A fruitful approach may be to utilize a microcomputer to improve target recognition, ground effect reduction, and gain control.

- Test other electrical and electromagnetic methods which detect changes in ground conductivity.

- Evaluate acoustic methods. Acoustic surveys can be time consuming and costly, but have some potential for effective use in waste detection. We recently performed an experiment at Hanford in which we successfully detected trench boundaries using acoustic holography. (3) 0ther innovative concepts may prove to effective and should be considered.

\subsection{MEASUREMENT OF BASALT DEPTH}

The use of the ground-penetrating radar technique for mapping the depth to basalt at the RWMC appears to be feasible. However, because of the shallow depth (approximately $1 \mathrm{~m}$ ) of the basalt bedrock at the test site (Site 4 ), we 
were not able to determine the maximum detection depth. As mentioned above, the reflected signal in our test data is masked by the ringing of the out-going signal. In future work, this could be avoided by using a higher radar frequency, possibly in the 300 to $500 \mathrm{MHz}$ range. A lower frequency, possibly 50 to $80 \mathrm{MHz}$, would extend the depth range if necessary.

It is not likely that layering in the basalt would be detectable. At the nearby observation well, the measured thickness of the basalt is approximately $100 \mathrm{ft}(32 \mathrm{~m})$, but it is not clear whether that thickness represents more than one flow. If shallow interbeds are present, they are probably thin and would be difficult to detect in a radar record. It may be possible to detect thick, shallow interfaces at other locations, but reflections from interfaces within the basalt will be weak because of the strong reflection at the uppermost basaltsediment interface. 


\subsection{GEOPHYSICAL SURVEY SYSTEM}

\section{1 BASIC SYSTEM DESIGN}

For the past several years, PNL has conducted a research and development program involving technology needed to characterize and evaluate burial sites containing radioactive waste materials. This work has been performed for the U.S. Department of Energy, and has been focused on waste burial sites within the Hanford nuclear reservation near Richland, Washington. However, the technology that has been developed under this program is applicable to the study of waste burial sites in other areas of the country as well.

The initial phase of the PNL program involved the evaluation of a broad spectrum of geophysical methods that appeared to have some potential for detecting and mapping buried waste materials. It was found that a combination of a metal detector, a magnetometer, and a ground penetrating radar could provide an effective and efficient survey system for burial ground mapping. However, it was evident that the volume of data that would be produced by these instruments in a detailed survey of a burial site would be too great to acquire, organize, and analyze by hand. Digital data recording and processing equipment is required.

Subsequentiy, a prototype geophysical survey system was designed and constructed. It includes the following major components:

- Metal Detectors. These are standard instruments, commonly used for locating underground pipes or for treasure hunting. In burial grounds where substantial quantities of metallic objects or waste containers have been buried, these instruments provide an effective initial survey capability. They are used in a hand-operated mode to quickly outline major concentrations of metallic wastes (Figure la).

- Magnetometer. This instrument detects only ferromagnetic (mainly steel) objects, but can often detect objects that are much smaller or deeper than those detectable by the metal detector. The system design includes a vehicle-mounted cesium vapor magnetometer (Varian Model VIW 2302C1) which is digitally interfaced to a microprocessor to provide a fast, 


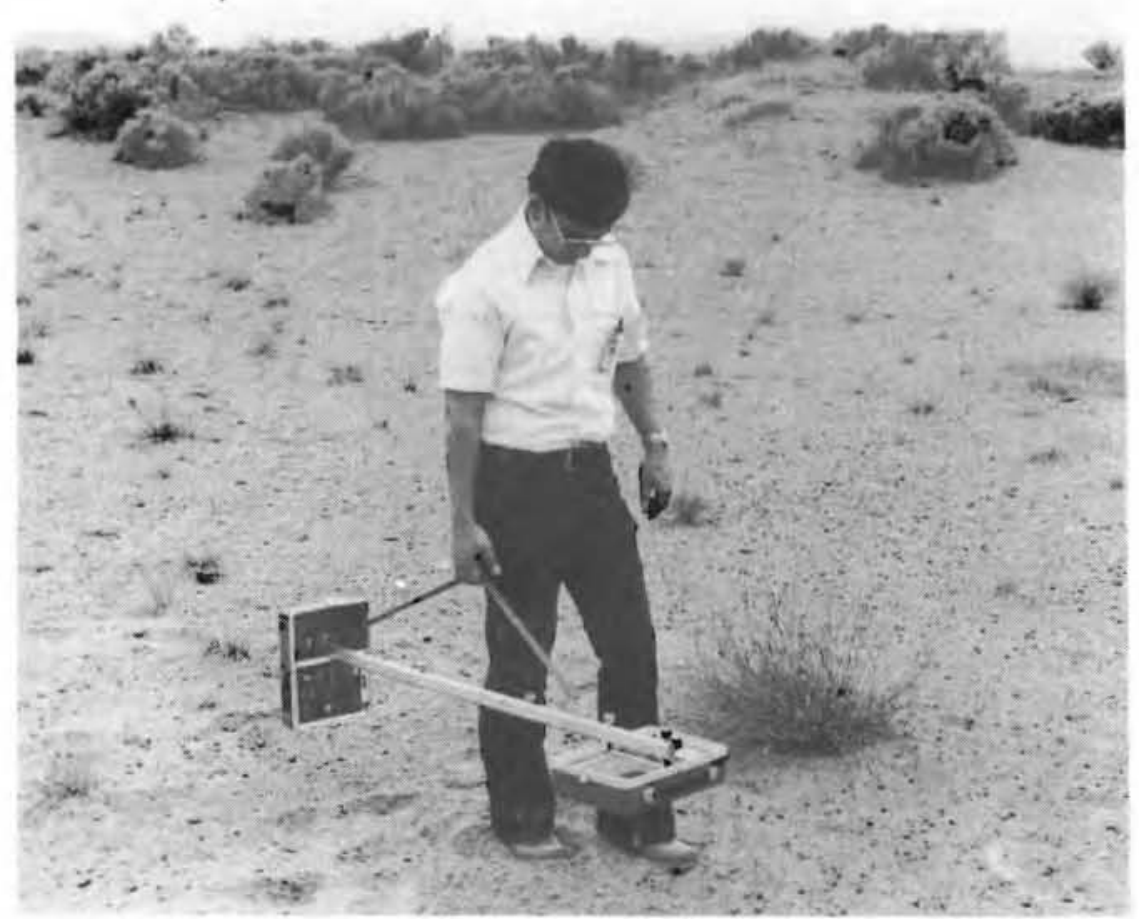

(a)

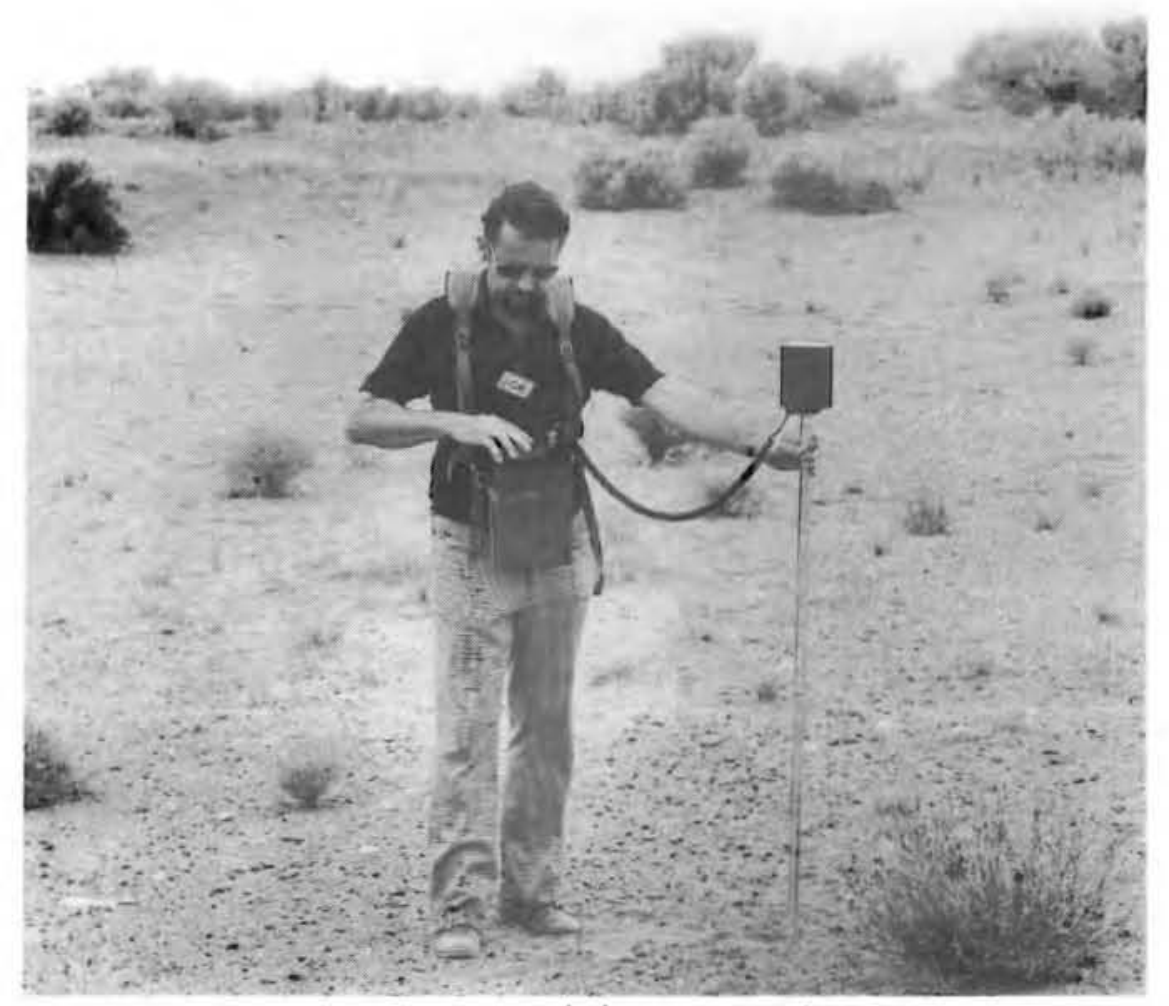

(b)

FIGURE 1. Survey Instruments Used in Burial Ground Surveys. a) Metal Detector. b) Proton Precession Magnetometer. 
computer-controlled data acquisition capability. However, this magnetometer was available only in a hand-operated mode for the RWMC survey. Magnetic measurements were also made by means of a hand-operated, Geometrics Mode1 G816 proton precession magnetometer (Figure 1b).

- Ground Penetrating Radar. A radar signal transmitted into the ground is reflected by objects or interfaces in the ground which correspond to changes in the dielectric constant. Buried waste materials, including both metallic and nonmetallic objects, generally produce abrupt changes in the dielectric constant and are therefore reflective. The radar unit in our survey system is mounted on the survey vehicle and is digitally interfaced to the microprocessor (Figure 2a).

- Survey Vehicle. This is a self-propelled, hydraulically powered vehicle which provides a means for transporting the magnetometer and radar unit, as well as necessary batteries and other electronic equipment. It is constructed almost entirely of nonmagnetic materials such as aluminum and stainless steel so that it will have a minimal influence on the surrounding magnetic field measured by the magnetometer. The microprocessor on the vehicle is a small computer which acts as both a data acquisition unit and a system controller. It collects data from the magnetometer and radar, then directs its transmission via a digital radio telemetry link to a larger computer installed in a nearby truck.

- Truck-Mounted Computer System. The data produced by the survey instruments is transmitted to this computer where it is processed, formatted, and stored on either a magnetic tape or a disk storage unit (Figure 2b). Preliminary data manipulation and processing functions can be performed on site to edit and compress the data for final storage or to facilitate data monitoring or previewing during a burial ground survey.

\subsection{METAL DETECTION}

Two commercial metal detectors were used in this survey. A Fisher Model TW-5 and a White's Coinmaster $V$ Supreme. The Fisher instrument is designed primarily for industrial applications and is normally used to 


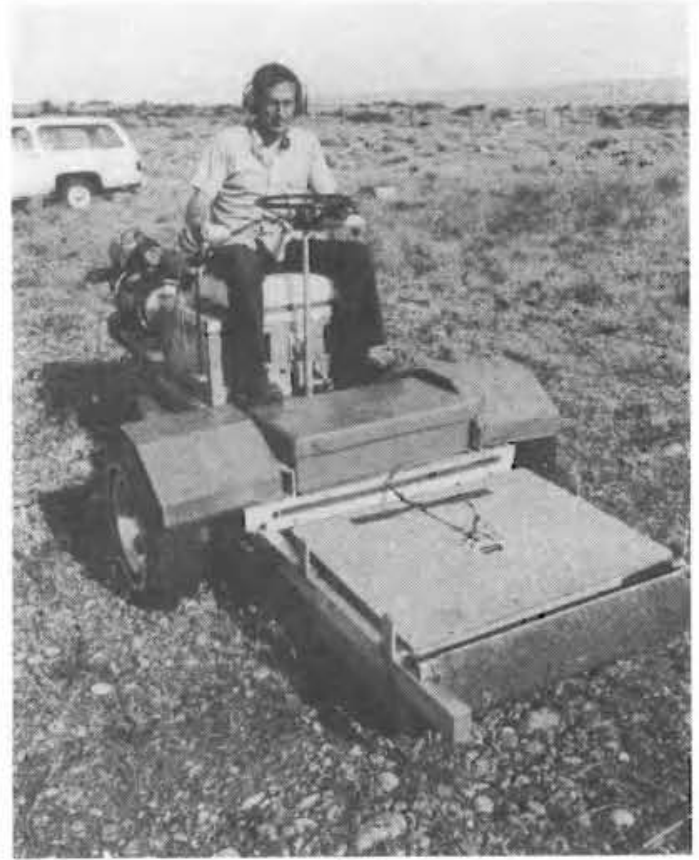

(a)

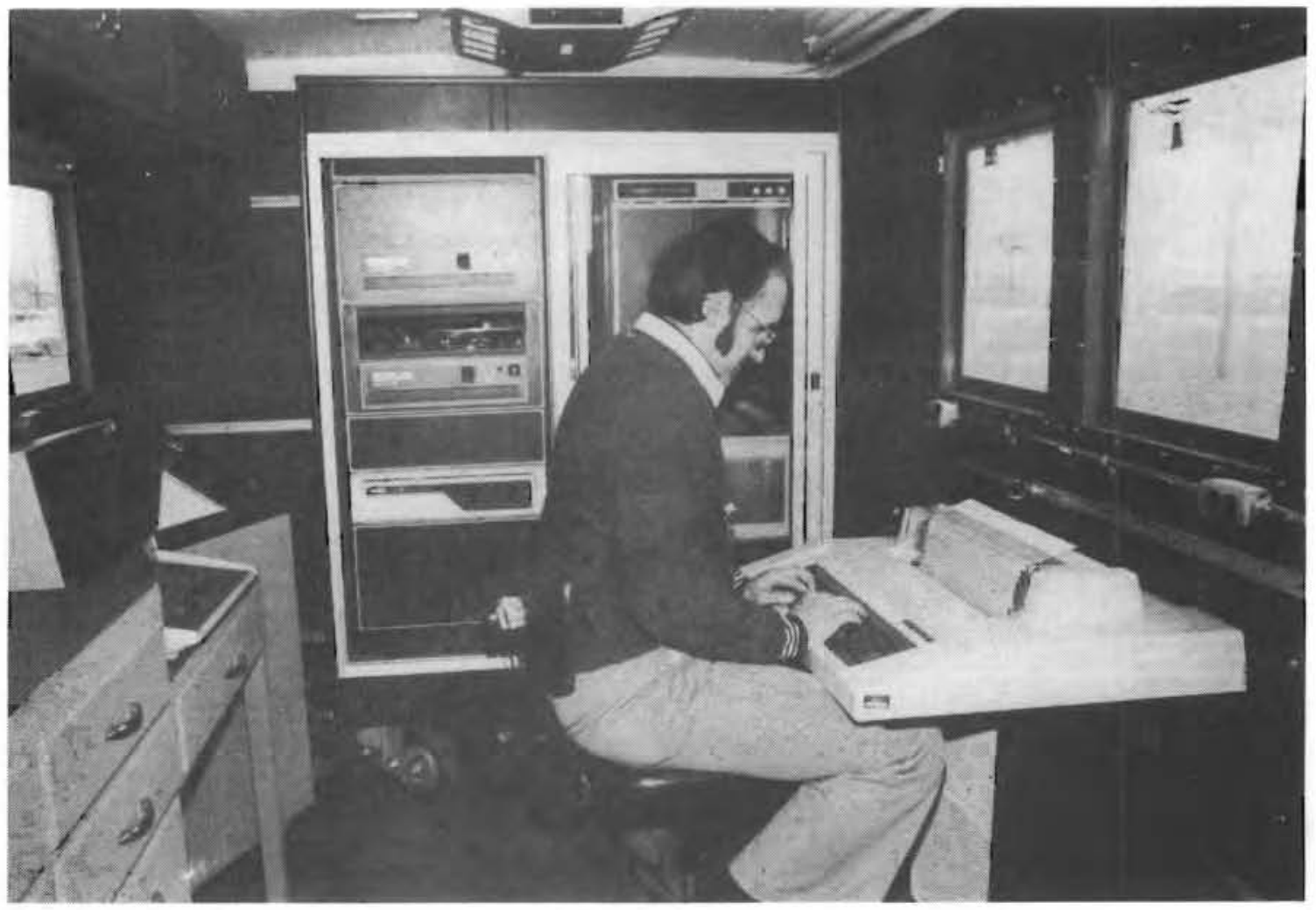

(b)

FIGURE 2. a) The Geophysical Survey Vehicle. The Radar Antenna is Mounted on the Front of the Vehicle. b) The TruckMounted Computer System. 
locate buried objects such as pipes or cables. The White's instrument is marketed mainly for the purpose of treasure hunting.

Both of these instruments operate on the induction balance, or transmitreceive, principle. That is, one (Fisher) or two (White's) transmitter loop coils and one receiver loop coil are geometrically arranged in such a way that a null or zero-induction condition is obtained in the absence of nearby metallic objects. When the coils are properly adjusted, the receiver is insensitive to the electromagnetic field of the transmitter. However, a signal will be detected if the electromagnetic field at the receiver coil is altered by the superposition of a secondary electromagnetic field resulting from induced currents in a nearby metallic object or conductive mass. Deviations from the balance condition are detected as electrical signals in the receiver and are electronically converted to a meter deflection as well as to an audible tone.

The Fisher metal detector is somewhat easier to adjust, and physically less tiring to use, than the White's instrument. Under certain conditions the latter may be slightly more sensitive. Both instruments have proven to be effective for reconnaissance surveys of waste burial sites.

Controlled tests at PNL have shown that the metal detectors are insensitive, even at short range, to elongated objects of smal1 cross section, such as a metal rod. More generally, the sensitivity and the effective penetration depth depend in a complicated manner on the shape, size, and orientation of the buried object. The test results indicate that the maximum depth at which a given object (not too elongated) can be detected by the metal detectors is typically two to four times its diameter, width, or other representative dimension.

\subsection{MAGNETIC FIELD MEASUREMENTS}

Magnetic field measurements can be used to locate buried ferromagnetic objects such as tools, steel containers, steel scrap, etc. This method is based on the fact that an induced magnetization is produced in any magnetic material within the earth's magnetic field. The induced field is superimposed 
on the earth's magnetic field and, if sufficiently large, can be detected as an anomaly or an aberration in the ambient field.

For a buried object, the induced magnetization per unit volume is given by

$$
I=\Delta k B_{0} \text {, }
$$

where

$$
\begin{aligned}
\Delta k= & \text { the difference in volume magnetic susceptibilities of the object } \\
& \text { and the surrounding material, } \\
B_{0}= & \text { the intensity of the earth's magnetic field. }
\end{aligned}
$$

The value and direction of $B_{0}$ are functions of location on the earth; most importantly they are functions of latitude (Figure 3). In the INEL area, $B_{0}$ is approximately .56 gauss, or 56,000 gammas $\left(1\right.$ gauss $=10^{5}$ gammas $)$. The inclination of the field is approximately $69^{\circ}$ (Figure 4 ) and the declination is approximately $17.5^{\circ}$ east. At this value of $B_{0}$, the susceptibility, $k$, of iron or steel objects is typically in the range 1-10 cgs units. The susceptibilities of naturally occurring rocks and sediments are normally several orders of magnitude smaller. Strongly ferromagnetic minerals, such as magnetite and $i 1$ menite, have susceptibilities in the range $0.1-0.8,(4)$ but these minerals comprise only a few percent of the volume of most sediments. Their effect on magnetic field measurements is usually negligible in surveys for buried steel objects.

The induced magnetic field of a buried object depends on the size, shape, depth of burial, orientation and susceptibility of the object, as well as on the direction and intensity of the earth's field. Analytical solutions for induced magnetic fields can be obtained for special object shapes such as spheres or cylinders, and it is generally possible to compute fields due to complex shapes by digital computer methods. (5-7) However, in the inverse calculation, which is the case of primary interest in geomagnetic surveys, no unique set of these parameters can be determined from a measurement of the magnetic field patterns. In other words, an indefinitely large number of combinations of parameter values will produce the observed magnetic anomaly. 


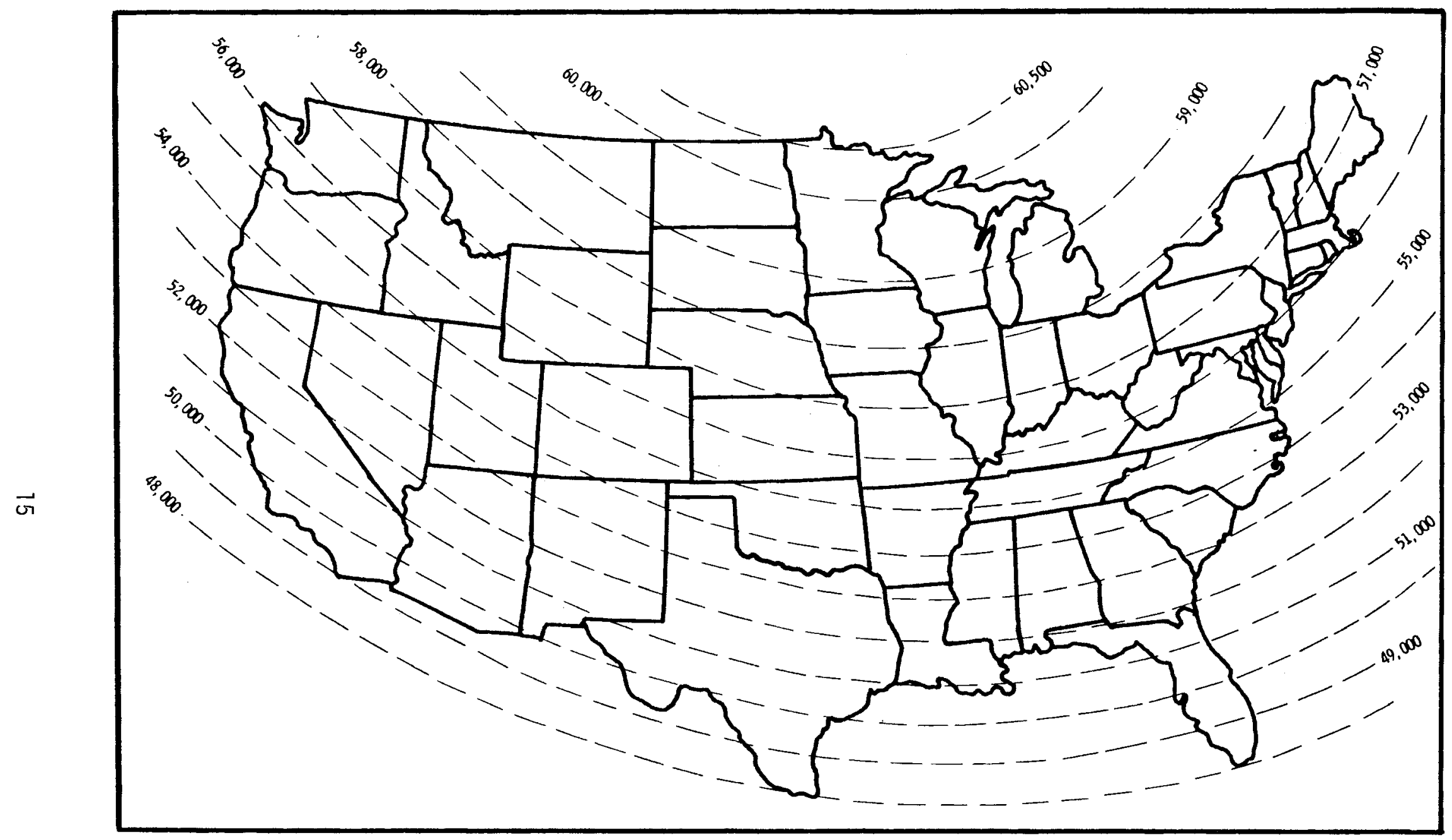

FIGURE 3. Map Showing the Intensity of the Earth's Magnetic Field. Adapted from U.S. Geological Survey Map No. I-915. 


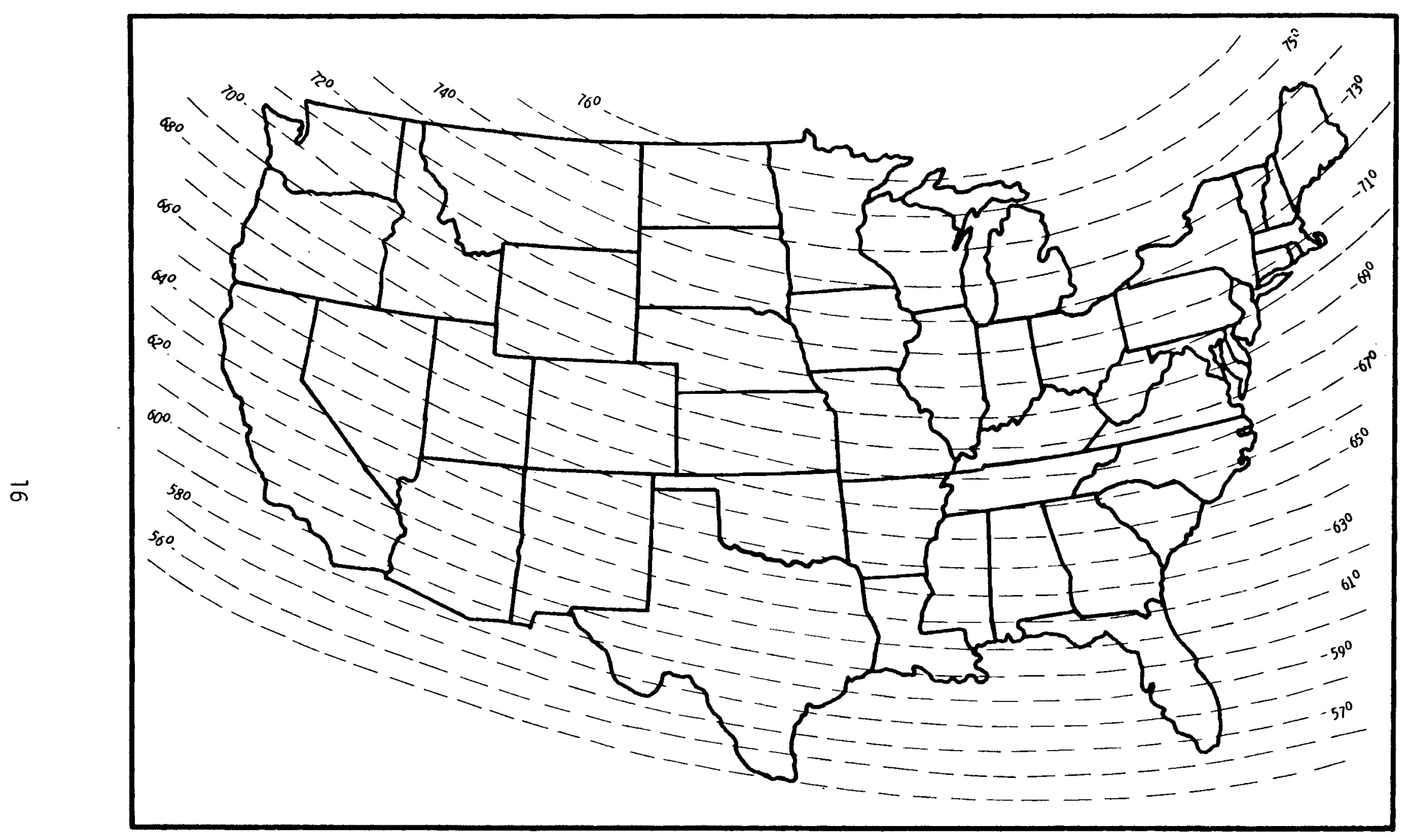

FIGURE 4. Map Showing the Intensity of the Earth's Magnetic Field. Adapted from U.S. Geological Survey Map No. I-912. 
This indeterminacy is characteristic of most geophysical methods. It is one of the factors that motivates a multifaceted approach to geophysical exploration programs.

A semi-empirical approach to magnetic interpretation is usually taken. Simple models are used to describe an object, and reasonable bounds, based on other available data, can often be placed on the parameter values. If a buried object is not too elongated, and if its magnetic field is observed at a distance several times greater than the width of the object, the field will be approximately the same as if the object were spherical. A spherical shell model for the calculation of magnetic anomalies is useful because only a simple coordinate tranformation is required to take into account the inclination of the earth's field.

Figure 5 illustrates the form of a magnetic anomaly calculated for a thinwalled steel sphere, $2.4 \mathrm{ft}(.7 \mathrm{~m})$ in diameter, buried at a depth of $6 \mathrm{ft}$ $(1.8 \mathrm{~m})$. Figure $5 \mathrm{a}$ is a contour map of the anomaly in a horizontal plane $4 \mathrm{ft}$ $(1.2 \mathrm{~m})$ above the surface of the ground. Figure $5 \mathrm{~b}$ shows two magnetic profiles along the $\mathrm{N}-\mathrm{S}$ traverses $\mathrm{A}$ and $\mathrm{B}$. An inclination angle of $68^{\circ}$ is used in this example. This is $1^{\circ}$ less than the actual inclination in the INEL area, but this difference is not significant for the purpose of this discussion. Four general characteristics of magnetic field anomalies due to discrete buried objects in the INEL area are illustrated:

1. The maximum of the anomlay lies to the south of the source. At the latitude of the INEL, the displacement is approximately one-third the source depth.

2. The width of the anomaly at one-half its maximum value is approximately equal to the source depth.

3. The maximum amplitude of the negative part of the anomaly is approximately one-tenth the amplitude of the positive peak and occurs approximately one depth unit to the north of the source.

4. The anomaly is very small (less than $2 \%$ of the maximum) at distances greater than three times the source depth. 


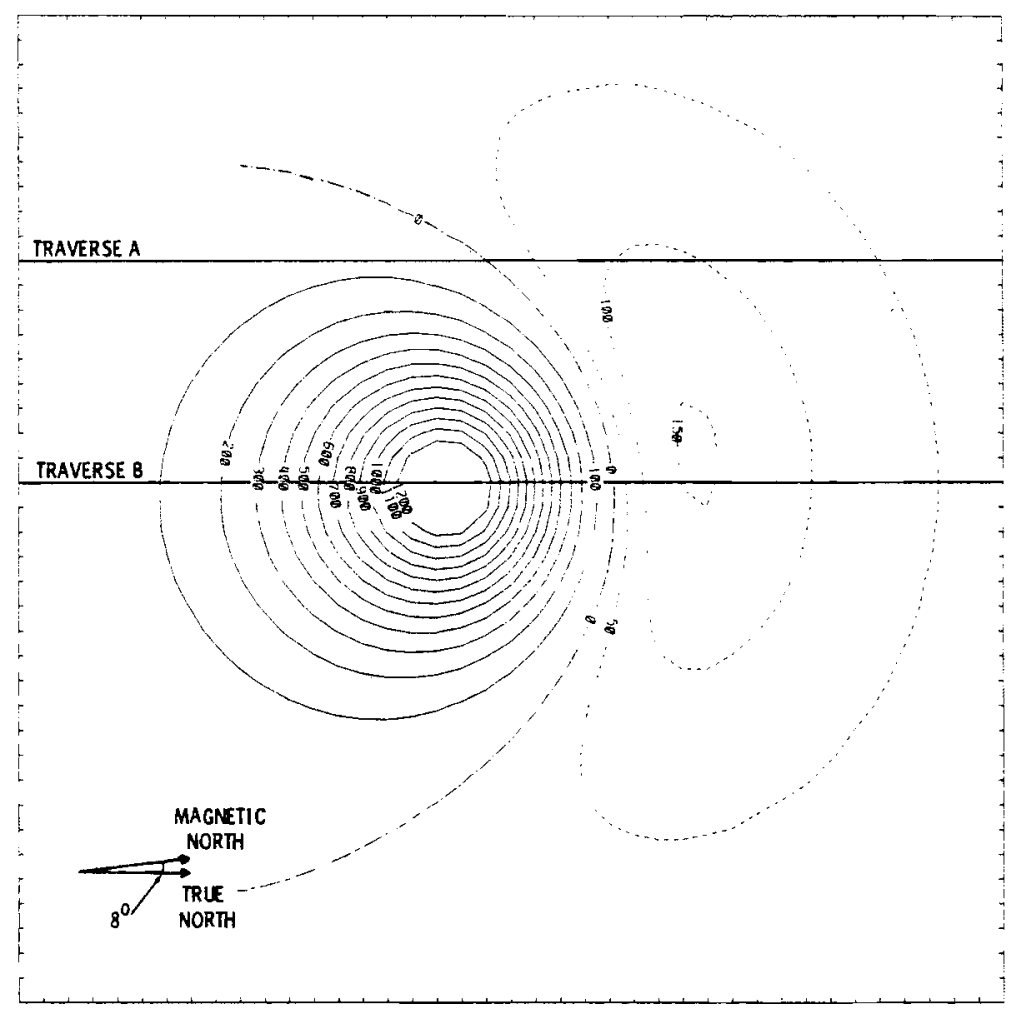

(a)

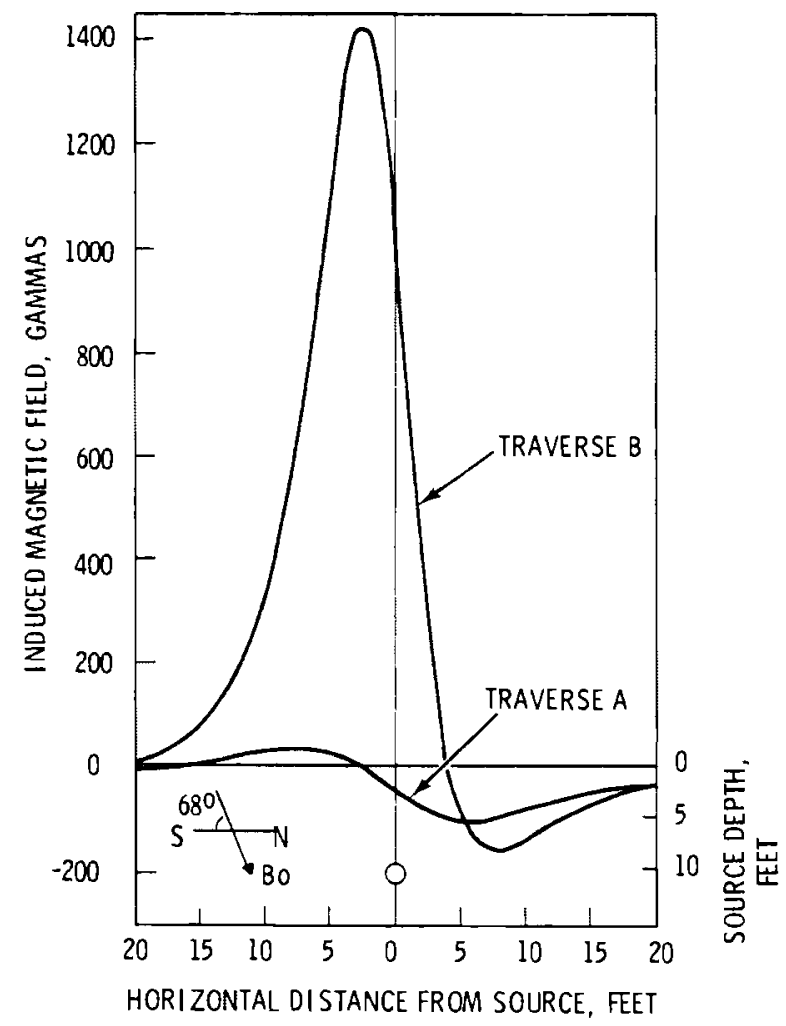

(b)

FIGURE 5. Calculated Magnetic Field Anomaly Due to a Thin-Walled Steel Sphere. a) Contour Map, $40 \mathrm{Ft}$ on a Side. The Source is at a Depth of $10 \mathrm{ft}$ in the Center of the Area. The Dashed Lines are Negative Contours. b) Magnetic Profiles Along Traverse Lines A and B. 


\subsection{GROUND PENETRATING RADAR}

Many aspects of radar technology have become highly advanced and sophisticated in recent years. Military applications and civil applications such as air traffic control, marine navigation, weather observation, and remote sensing, have stimulated major advancements in radar technology. Recent developments in electronics and data processing equipment have enhanced the reliability, power and flexibility of radar systems. However, these remarks apply primarily to radar systems designed for above-ground applications. Although downward-looking radar devices have been used for many years, there has not been the same intensity of effort to develop these systems as there has been to develop above-ground systems.

The potential applications of ground penetrating radar are numerous. Examples include the detection, identification and mapping of buried nuclear and chemical wastes, assessment of underground nuclear waste repository sites, detection of underground pipes and cables, geologic mapping, studies of glacial ice and sea ice, detection of mining and tunneling hazards, and archeological surveys.

In applications such as these, which involve the determination of depths to interfaces or the detection and characterization of discrete objects or underground structures, resolution requirements demand the use of short radar wavelengths, generally less than 10 meters. Unfortunately, many ground materials are strong absorbers of electromagnetic energy at short wavelengths. Strong absorption by the ground usually requires the use of radar wavelengths greater than about 0.5 meter.

The attenuation of a propagating plane electromagnetic wave in a dielectric medium such as the earth is given by the expression, (9)

$$
E=E_{0} e^{-\alpha x},
$$

where

$$
\begin{aligned}
& E_{0}=\text { the initial electromagnetic field intensity, } \\
& \alpha=\text { the absorption coefficient } \\
& x=\text { the propagation distance. }
\end{aligned}
$$


It is convenient to express the absorption in terms of decibels per meter. The absorption loss, $A$, is given by

$$
A=20 \alpha / 2.3=8.7 \alpha \mathrm{db} / \mathrm{m} .
$$

Then

$$
E=E_{0} e^{-0.115 \mathrm{Ax}} \text {. }
$$

The absorption coefficient is strongly frequency dependent and is a function of the electrical conductivity, the magnetic susceptibility or permeability, and the relative dielectric constant of the medium. For a medium of negligible magnetic permeability this relationship is given by $(10)$

$$
\alpha=.0148 \mathrm{f} \sqrt{\mathrm{K}}\left(\sqrt{1+\tan ^{2} \delta}-1\right)^{1 / 2} \mathrm{~m}^{-1},
$$

where

$$
\begin{aligned}
& \tan \delta \text { (the loss tangent) }=18 \mathrm{~B} / \mathrm{Kf}, \\
& K=\text { the relative dielectric constant, } \\
& \beta=\text { the conductivity of the medium (millimhos } / \mathrm{m} \text { ), } \\
& f=\text { frequency }(\mathrm{MHz}) .
\end{aligned}
$$

The water content of the ground is the most important factor affecting electromagnetic absorption loss. An increase in moisture content of the soil or other ground material greatly increases both the electrical conductivity and the dielectric constant of the ground. The magnitude of the effect of ground moisture depends on the composition and porosity of the ground material. The dielectric constant at normally used ground-penetrating radar frequencies is generally in the range 3-30 as illustrated in Figure 6 . The dielectric constant of most dry soils or rocks is in the range 3-10. The dielectric constant of pure water is 81 .

Measured values of absorption loss as a function of frequency and soil moisture are shown in Figure 7 . These are laboratory measurements made on a sandy soil from the Hanford area. The expected absorption loss for a saturated volume of this material would be about $8 \mathrm{db} / \mathrm{m}$ at $100 \mathrm{MHz}$. Equivalent measurements were not made for the saturated soil at the RWMC 


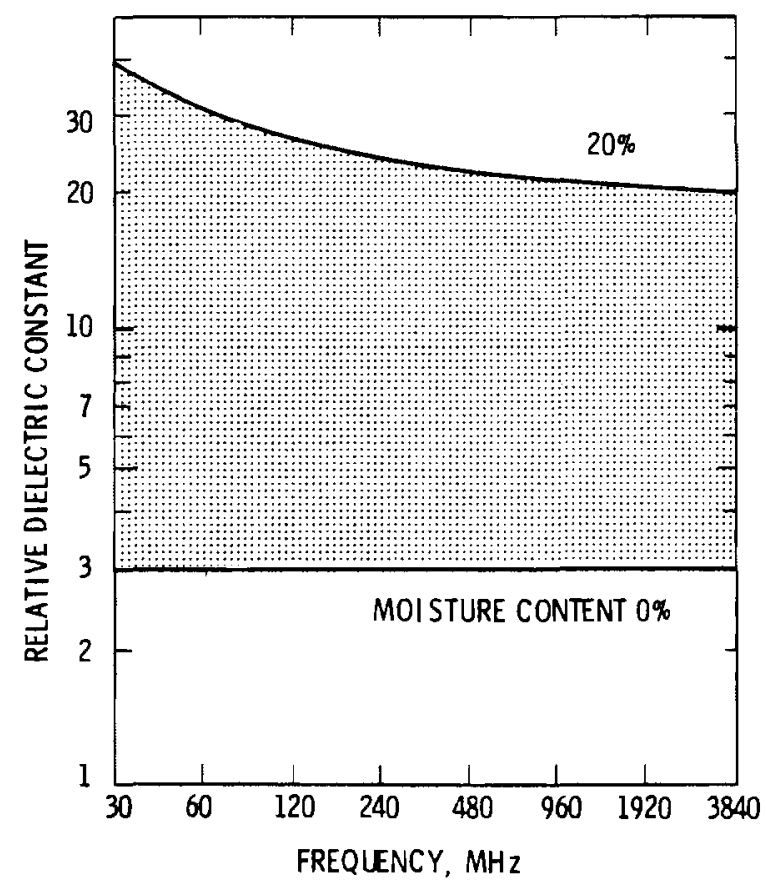

FIGURE 6. The Relative Dielectric Constant of Typical Soils for Moisture Content in the Range $0-20 \%$ by Weight. $20 \%$ Corresponds to Saturated Soi 7 .

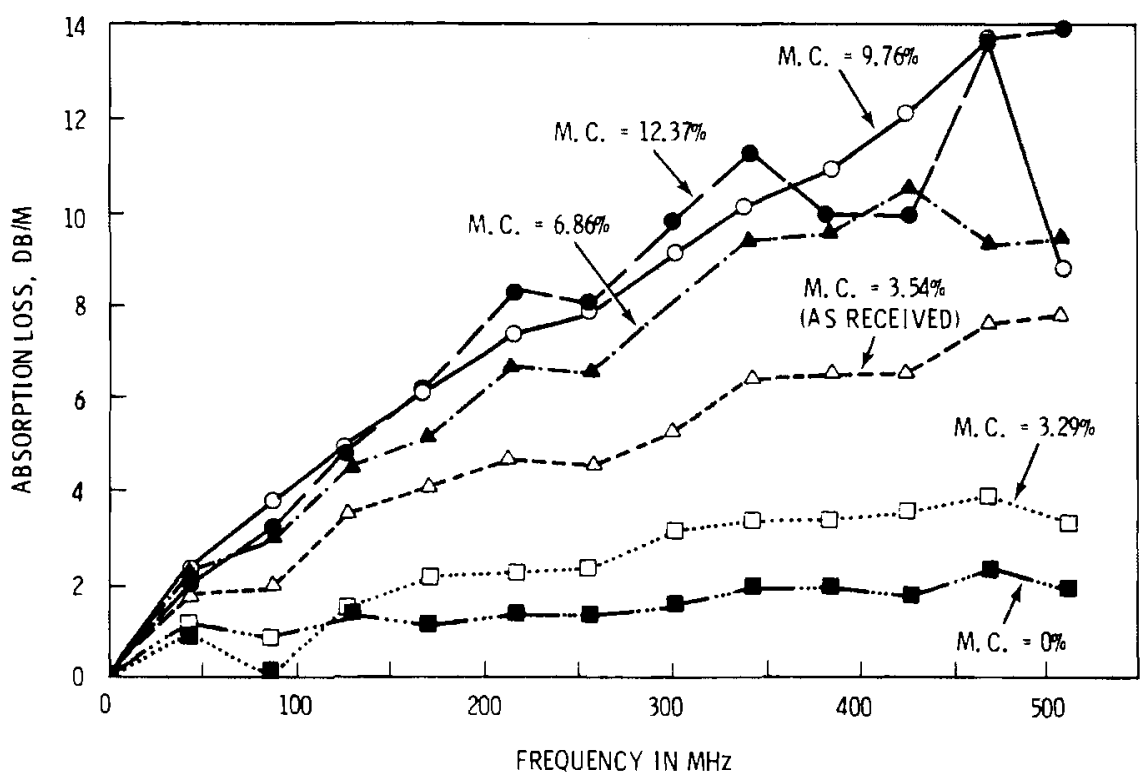

FIGURE 7. Measured Values of Radar Signal Absorption Loss Versus Transmitted Frequency for Several Values of Moisture Content. The Soil Sample was from the Hanford Area. 
site; however, field observations of radar performance indicate that the absorption loss was similar to that experienced at Hanford. The performance of the radar system will be further discussed in a later section of this report.

Additional loss factors which affect the performance or effectiveness of a given ground penetrating radar system include reflective losses at the air-ground interface, geometrical spreading of the transmitted radar beam, the effective backscattering cross section of the reflective target, and the spreading of the reflected signal. A positive factor is a refractive gain due to the focusing effect of the dielectric medium.

Radar signals are reflected or backscattered by objects or interfaces which have a dielectric constant different from that of the surrounding medium. The reflection coefficient for a radar signal normally incident on an infinite flat interface between dielectric media 1 and 2 is given by

$$
R=\frac{\sqrt{K 2}-\sqrt{k 1}}{\sqrt{K 2}+\sqrt{k 1}} .
$$

This term represents a maximum reflectivity. Discrete objects of irregular shape will be less reflective and will also tend to scatter energy in all directions, whereas the infinite flat plane is a specular reflector.

The radar system utilized by PNL for burial ground surveys is a commercially available unit manufactured by Geophysical Survey Systems, Inc., (GSSI). This is an impulse radar designed for time-domain reflectometry. A single dipole antenna, suspended approximately 1.5 inches $(4 \mathrm{~cm})$ above the ground, is used for both transmitting and receiving. A short electromagnetic pulse, approximately 10 nanoseconds in length, is transmitted into the ground (Figure $8 \mathrm{a}$ ). The half-power points of the transmitted spectrum are at approximately 50 and $170 \mathrm{MHz}$ (Figure 8b).

Energy reflected from buried objects is received by the antenna (electronically switched to the receiving mode) at arrival times proportional to the depth of burial. The reflected signal is digitally sampled at 120 equally spaced points by the microprocessor in the survey vehicle. The digitized waveforms, or pings, are transmitted to the truck-mounted computer 


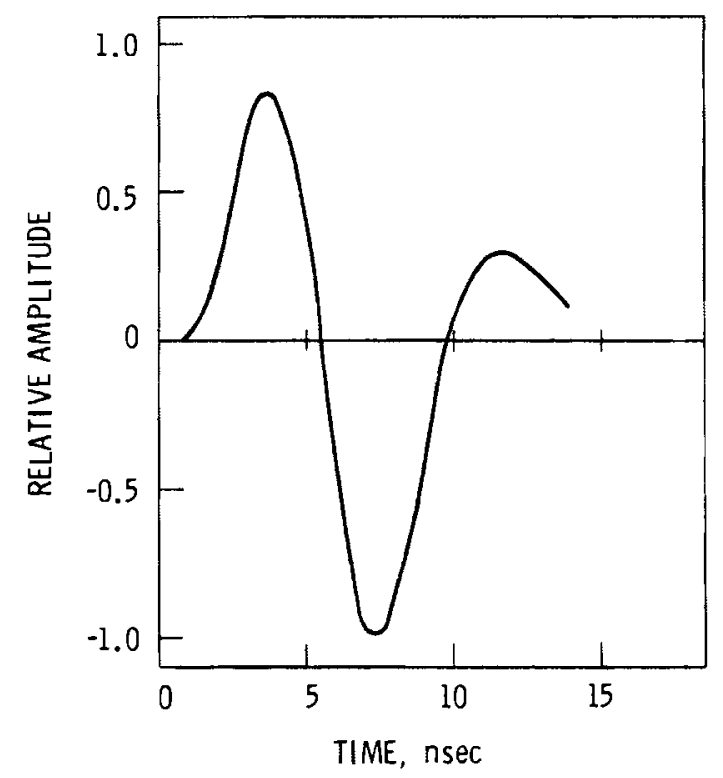

(a)

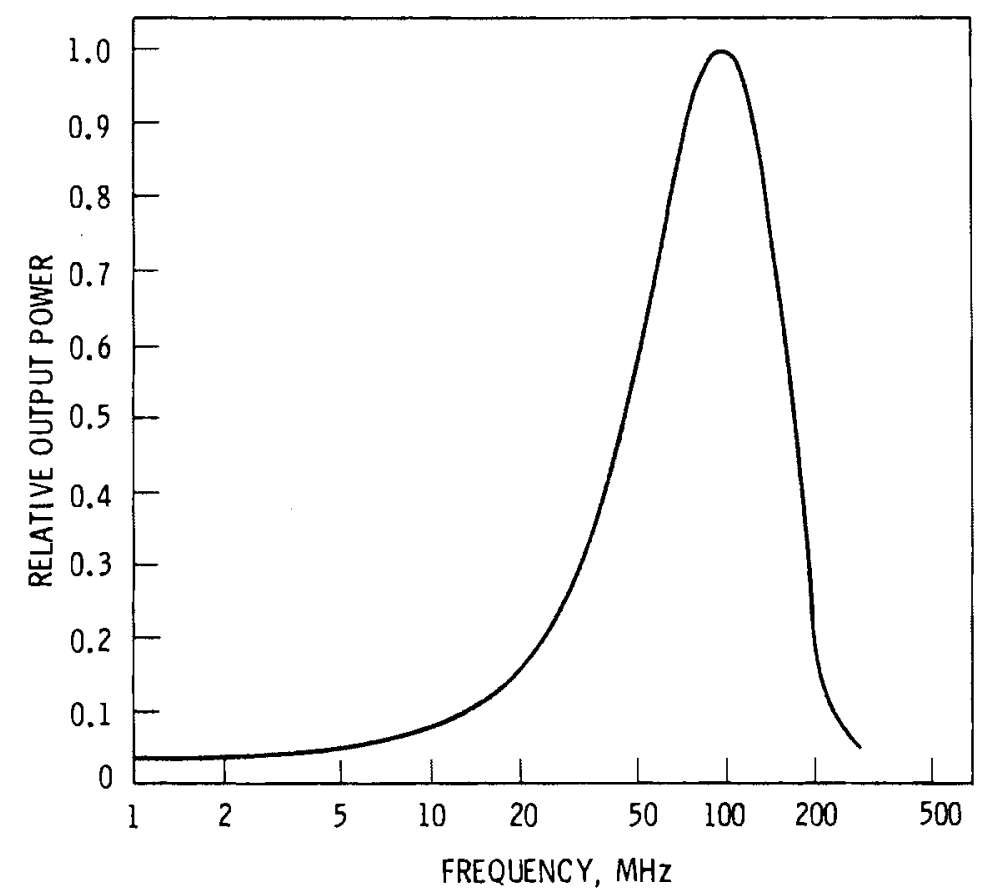

(b)

FIGURE 8. a) The Waveform Transmitted by the GSSI Radar. b) The Power Spectrum of the Signal Shown in a). 
where they are stored for subsequent processing and analysis. The survey vehicle is driven along predetermined tracks across the area to be surveyed. Radar pings are digitized and transmitted approximately every 4-6 inches $(10-15 \mathrm{~cm})$ along a track. A track spacing is selected to provide both good target resolution and a satisfactory rate of areal coverage. A spacing of from 2 to $5 \mathrm{ft}(.6$ to $1.5 \mathrm{~m})$ is usually appropriate.

The present state-of-the-art in ground-penetrating radar measurement and data interpretation is such that under the conditions commonly experienced in field surveys, it is often difficult or impossible to determine the size, shape or composition of a buried reflective object. Research and development efforts will undoubtedly result in improved ground-penetrating radar system capabilities and data analysis procedures in the future. At the present time, measurement devices such as metal detectors and magnetometers can provide usefui supplementary information about objects or materials detected and mapped by available radar systems. 


\subsection{DATA PROCESSING AND DISPLAY}

As received and recorded by the computer in the field truck, the radar data are not in an optimal form to be displayed and interpreted. Subsequent digital data processing programs can enhance the quality and usefulness of the data. We have developed several computer programs to enhance and display the radar and magnetometer survey data.

Figure 9 is a flow chart showing the computer programs involved in the data recording/processing/display sequences for radar and magnetometer data. The GEOSUR and IDA programs are for recording and manipulating the data after it has been transmitted to the computer from the survey vehicle. In this project they were bypassed for the handling of magnetic data because the magnetic measurements were made manually.

\subsection{RADAR DATA}

As described earlier, burial ground surveys are performed by driving the survey vehicle along predetermined parallel traverse lines, or tracks. Radar data in the form of 120-point pings are acquired at equally spaced locations along the tracks. For a typical track length of $100 \mathrm{ft}(30.5 \mathrm{~m}), 200$ to 300 pings will usually be acquired, depending on the speed of the survey vehicle. The exact number is specified on the basis of a trial run. The received data are interpolated by the IDA program to obtain the specified number. The IDA data format groups the survey data (including position coordinates and magnetic field values) into 256-word (51.2-byte) blocks. A radar ping consists of the last 120 bytes in each 128-byte record. Because of this format, it was convenient from a programming standpoint to require that the number of pings in each track be a multiple of four.

The stored digital radar data can be thought of as a three-dimensional array containing 120 bytes per ping, $N$ pings per track, and $M$ tracks. The data processing programs REMVH and HYPER operate on two-dimensional radar data; that is, they operate on each track in sequence. Program SLICE operates on the entire three-dimensional array to construct a two-dimensional array. 


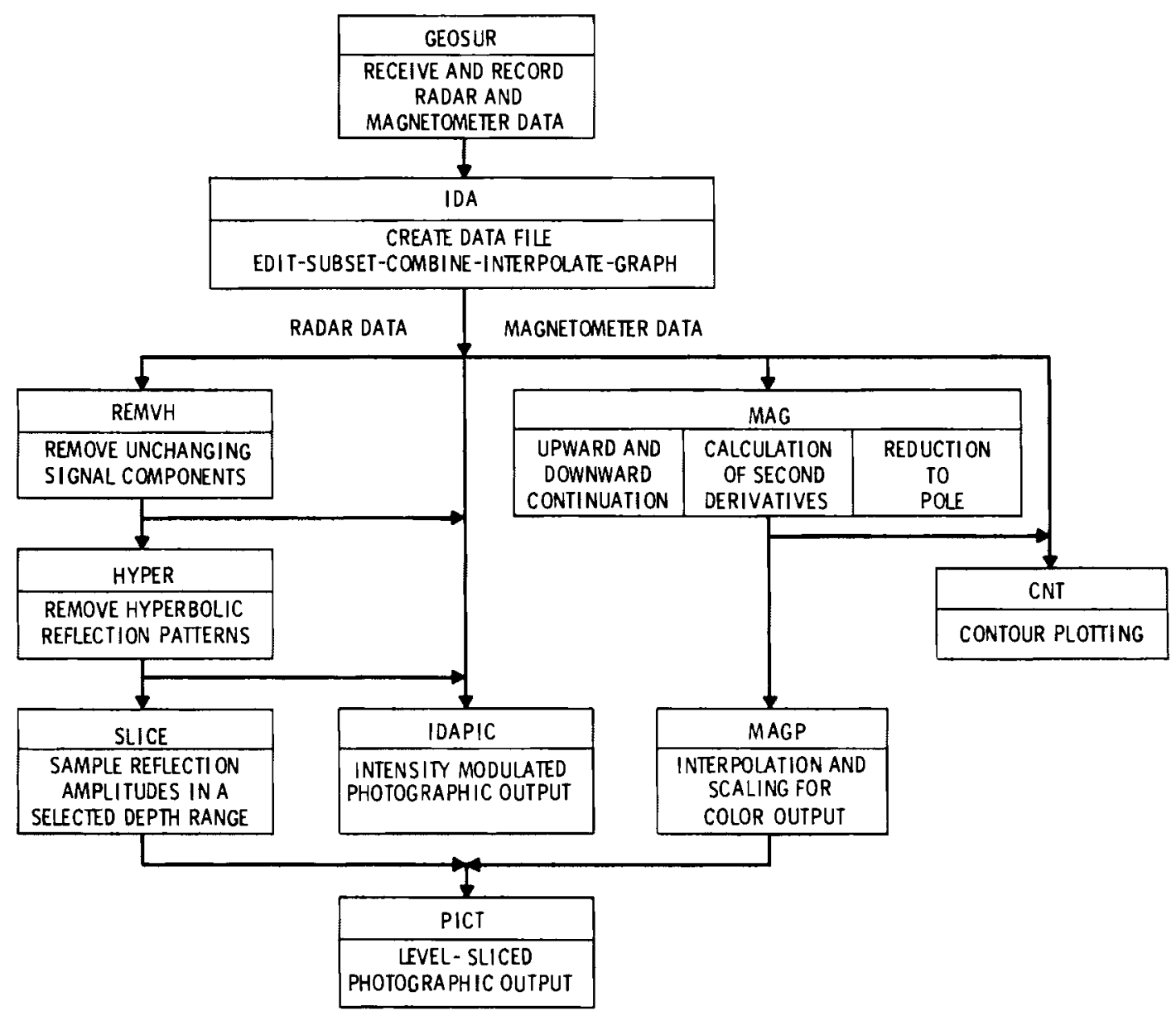

FIGURE 9. Computer Program Flow Chart for Radar and Magnetometer Data.

\subsubsection{Program REMVH}

A characteristic of the reflected radar signals is that they contain components that are unchanging from ping to ping and convey no information about subsurface reflectors. These components are due to a combination of factors: the oscillatory shape of the waveform, the presence of a ground surface reflection, random reflections from the survey vehicle and the radar 
unit itself, and electronic effects in the radar unit. These unwanted signal components appear in a radar image as alternately bright and dark horizontal bands. The upper image in Figure 10 illustrates this effect. In each image of Figure 10, the horizontal dimension corresponds to distance along the traverse line, and the vertical dimension is proportional to the travel time of the radar signal (or to depth).

The purpose of program REMVH is to remove the banding due to stationary signal components. Let $I(1 \leq \mathrm{I} \leq 120)$ be the datum index in a given ping, and let $\mathrm{J}(1 \leq \mathrm{J} \leq \mathrm{N})$ be the ping index in a given track ( $N$ is the number of pings in the track). For each fixed value of $I$, the program computes a running histogram as it scans the array in the $\mathrm{J}$ direction. At a given point, $(I, J)$, in the array, the running histogram includes all data within the bounds $I 1=I-1$ to $I 2=I+1$ and $J 1=J-J A / 2$ to $J 2=J+J A / 2$, where $J A$ is a specified number. At the edges of the array, the bounds are as follows: if $I=1, I 1=1$; if $\mathrm{I}=120$, I2 $=120$; if $\mathrm{J}=1$, J1 $=1$; and if $\mathrm{J}=\mathrm{N}, \mathrm{J} 2=\mathrm{N}$. The banding is removed by computing an average value from the data within the bounds of the running histogram, then subtracting the average from datum I,J. However, if the row contains values that are substantially higher or lower than the average value, this simple procedure can yield local correction values that are either too high or too low. This has the effect of introducing a spurious horizontal oscillation in the data. The histogram provides a simple means for excluding a range of high and low values. Improved corrections are typically obtained by excluding the highest and lowest $10 \%$ of the data from the calculation of the average.

The middle image in Figure 10 shows the effect of applying program REMVH to the raw radar data. This approach to radar image enhancement improves the detectability of discrete buried objects or irregular masses of waste material, but it is not effective in cases where it is necessary to detect flat, horizontal interfaces.

\subsubsection{Program HYPER}

The function of this program is to remove hyperbolic reflection patterns from radar images, or reflection profiles. Hyperbolic patterns occur because 

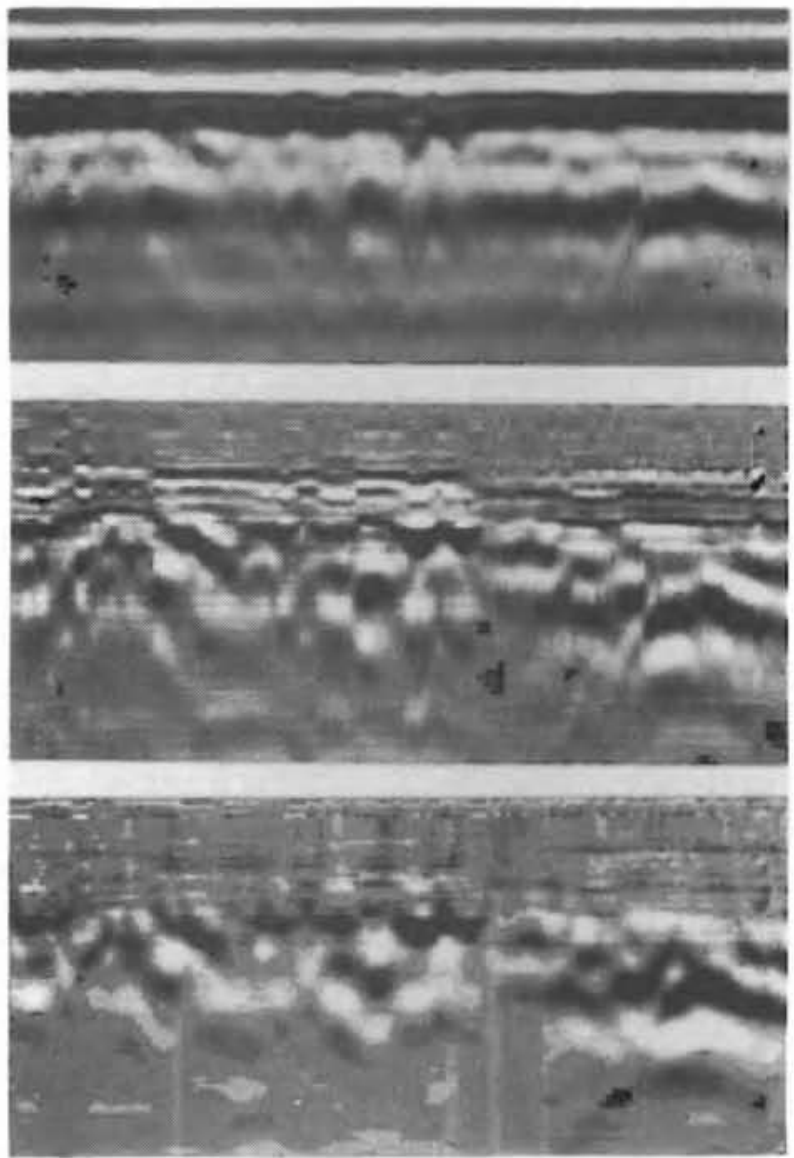

FIGURE 10. Three Forms of One Radar Profile Illustrating Computer Processing Operations. From Top to Bottom: Unprocessed, Processed by REMVH, and Processed by REMVH and HYPER. 
a radar output beam has a finite angular width. Reflections are therefore received from a buried object both before and after the sensing transducer passes directly over it. It is sometimes desirable to remove the hyperbolic patterns from the radar profiles because they can increase the difficulty of interpreting the data.

As indicated in the flow chart of Figure 9, the next data processing procedure applied to the radar data after program HYPER is the construction of twodimensional arrays which represent map views of the radar reflections in a selected depth range. In that procedure, the hyperbolic patterns will produce erroneous indications of reflecting objects. It is therefore important that they be removed from the reflection profiles.

The approach taken in program HYPER is (in effect) to gather the energy within a hyperbola into the point at its apex. Each datum in each ping is treated in turn as the apex of a hyperbola. If a datum does in fact correspond to a reflection point, its amplitude will be enhanced by adding to it the other data that lie along its reflection hyperbola.

If a datum does not correspond to a reflection point, values along its hyperbola will tend to cancel each other because of the oscillatory character of the waveform.

The reflection patterns fit the equation

$$
t=\sqrt{\left(\frac{2 x}{v}\right)^{2}+t_{c}{ }^{2}}
$$

where

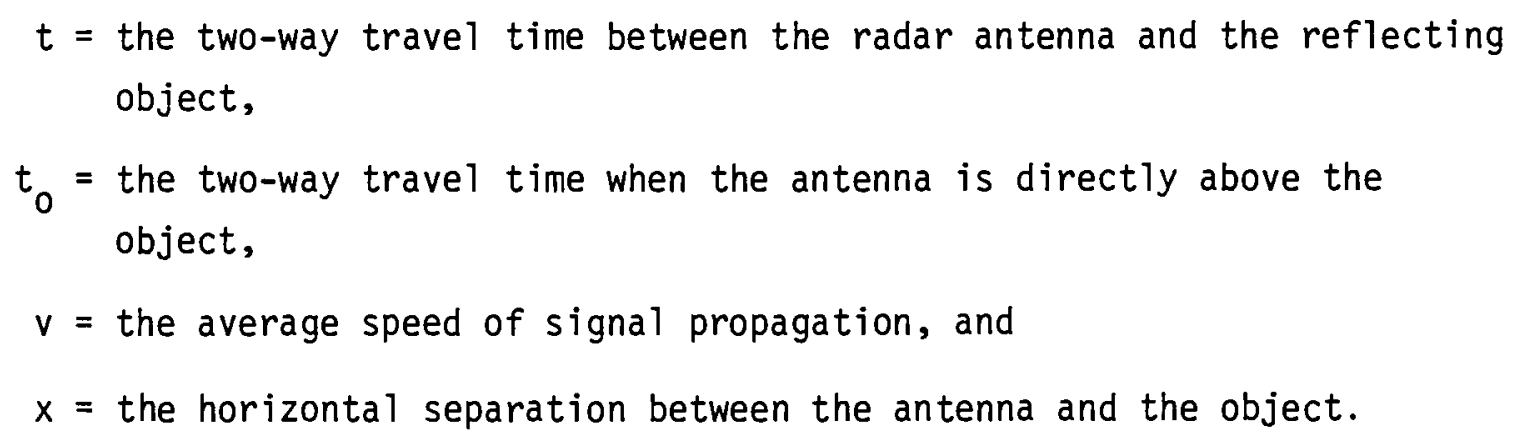


The upper part of Figure 11 illustrates the reflection geometry; the lower part shows its relationship to a hyperbolic travel time curve.

For programming purposes, it is convenient to write the above equation in the form $M=\sqrt{(A \cdot J)^{2}+M 0^{2}}$, where $M$ is the datum index in a given ping, $J$ is the distance to the apex of the hyperbola in terms of the number of pings, $M O$ is the index of the datum at the apex of the hyperbola, and $A$ is a constant proportional to the signal propagation speed in the ground.

The value of $A$ can be readily determined on the basis of a best fit to the reflection patterns. It can also be calculated using a measured value of the signal propagation speed.
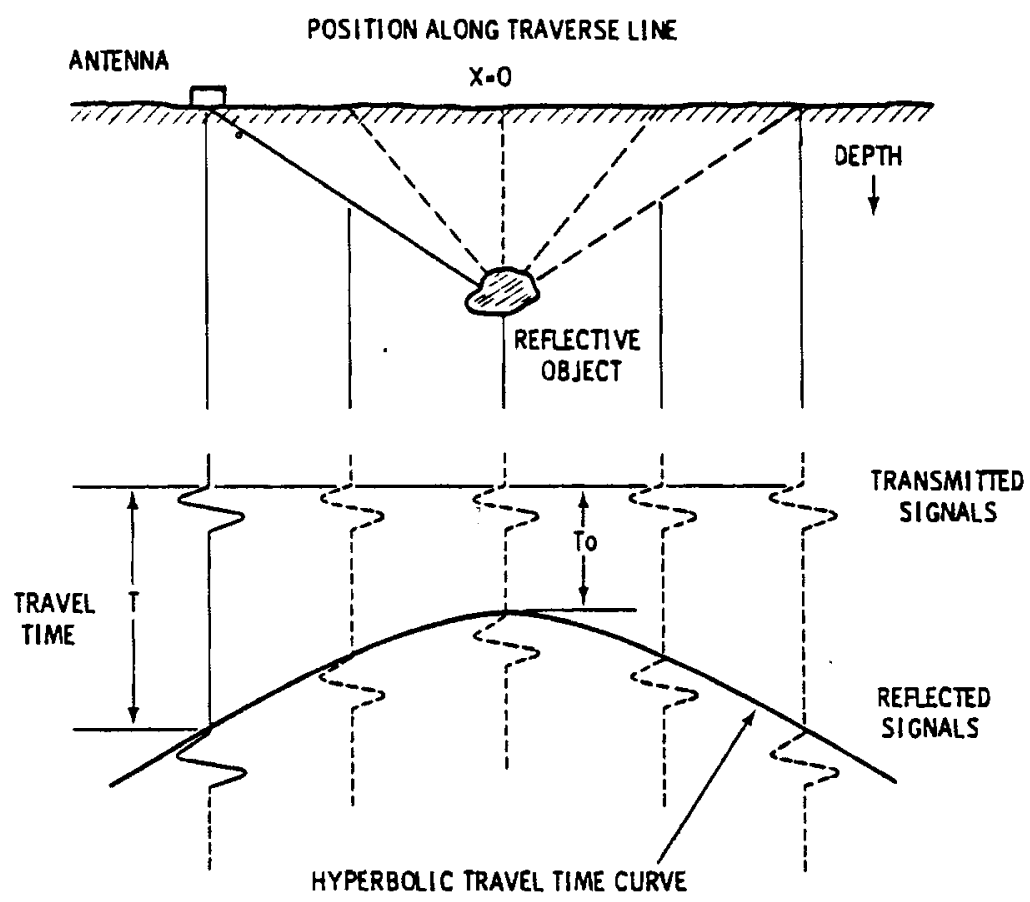

FIGURE 11. Reflection Geometry for Ground-Penetrating Radar Profiling and the Occurrence of Hyperbolic Reflection Patterns. 
The bottom image in Figure 10 shows the sample radar reflection profile after removal of the hyperbolas. The basic procedure in program HYPER is equivalent to migration techniques used to process seismic reflection profiles. $(12,13)$ The effects of beam width and geometry on the reflection profile are the same for both seismic and radar waves.

\subsubsection{Program SLICE}

Ground-penetrating radar surveys normally involve cumbersome methods for mapping detected buried objects. The locations of buried objects are usually determined visually from a collection of radar profiles, then manually transcribed to a map. The purpose of program SLICE is to utilize a digital computer to accomplish the same task.

Burial ground surveys can involve the collection of radar data over very large areas. In addition, numerous closely spaced traverses are needed in order to obtain detailed information on the locations of the buried materials. Therefore, a computer method for deriving and displaying this information can be highly efficient in comparison with manual methods.

Program SLICE is essentially a routine to construct a selected twodimensional data array from the original three-dimensional array. A depth range is specified in terms of data indices which range from 1 to 120 . Then for each ping in the array, a new array element is derived by averaging the ping over the specified depth range. The dimensions of the new array are $N \times M$, where $N$ is the number of pings per track and $M$ is the number of tracks. Because the original data spacing along a survey track is much less than the track spacing, it is necessary to expand the new array in the across-track direction. This is accomplished by linear interpolation. Interpolation in both directions allows the array size to be completely selectable.

The storage disk file structure of the output data is different from that of the IDA-produced files. Because of the arbitrary record size, it is not convenient to adhere to the four-record per block format used by IDA. Each interpolated data track, or row, is individually stored in one or more 512-byte blocks. 
In cases where the distribution of buried objects is sufficiently sparse to allow radar reflections from a wide range of depths, a single, thin, horizontal slice will show only those objects contained in the corresponding narrow depth range. Examples of the output of program SLICE are shown in Section 5 .

\subsubsection{Program IDAPIC}

Preliminary hardcopy displays of raw and processed radar data can be made almost in real time by means of a data previewing capability included in program IDA. Final output products, however, are made in photographic form by utilizing a DICOMED D48, black and white or color, digital film recorder. This is a computer peripheral device associated with the laboratory computer system of the Water and Land Resources Department at PNL.

The function of IDAPIC is to transmit IDA formatted radar data to the film recorder. It provides options for file subsetting, image contrast enhancement, and color-coded level slicing.

\subsubsection{Program PICT}

This is a general purpose program for producing photographic images of raster-scan data from a wide variety of sources. In particular, it accepts the file structure of the output data produced by program SLICE. It is otherwise similar in both form and function to program IDAPIC.

\subsection{MAGNETOMETER DATA}

The data acquisition system on the survey vehicle is designed to transmit either one or two magnetic field values along with each transmitted radar ping. Two magnetic field values are allowed in order to provide for the possible future use of two magnetometers. However, only one will be used under present program plans. The magnetometer data is, therefore, basically a two-dimensional layer in the three-dimensional IDA data array.

\subsubsection{Program MAG}

Numerous methods for analyzing magnetic data have been described in the literature. Commonly, these methods involve data manipulation operations 
such as upward and downward continuation of the magnetic field, calculation of vertical derivatives, and reduction to the pole. Program MAG follows the

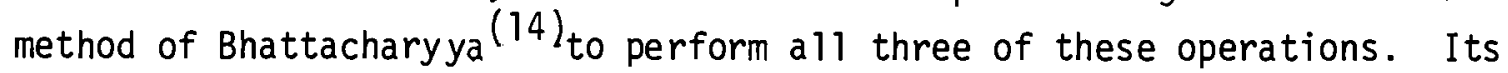
basic function is to systematically alter or enhance the magnetic field patterns in such a way that they can be more easily interpreted.

In a region free of magnetic materials, the total magnetic field anomaly, $\Delta B$, satisfies Laplace's equation; that is:

$$
\frac{\partial^{2}(\Delta \mathrm{B})}{\partial x^{2}}+\frac{\partial^{2}(\Delta \mathrm{B})}{\partial y^{2}}+\frac{\partial^{2}(\Delta \mathrm{B})}{\partial z^{2}}=0
$$

By the method of separation of variables, the solution of this differential equation can be expressed as:

$$
B(x, y, z)=\sum_{m} \sum_{n} f\left(\frac{m x}{L_{x}}, \frac{n y}{L_{y}}\right) \exp \left[-2 \pi\left(\frac{m^{2}}{L_{x}^{2}}+\frac{n^{2}}{L_{y}^{2}}\right)^{1 / 2} \cdot z\right]
$$

where

$f\left(\frac{m x}{L_{x}}, \frac{n y}{L_{y}}\right)$ is a two-dimensional Fourier series expansion of the magnetic field in the measurement plane $z=0$,

$L_{x}=M \Delta x$

$L_{y}=N \Delta y$

$M$ and $N$ are the number of data in the $x$ and $y$ directions, respectively, and $\Delta x$ and $\Delta y$ are the data spacings in the $x$ and $y$ directions, respectively.

Upward and downward continuations of a magnetic anomaly are calculated by inserting the appropriate values of $z$ into the above summation. Vertical derivatives of $\triangle B$ are calculated by differentiating the exponent within the summations.

\subsubsection{Program CNT}

Program CNT is a system routine on PNL laboratory computers. Its function is to plot contour maps from various kinds of data arrays. Hardcopy output products are typically drawn on a Calcomp plotter. 


\subsubsection{Program MAGP}

It is often useful and desirable to display magnetic data in the form of a color picture. This is conveniently accomplished by means of program PICT. However, the number of magnetic measurements made in a given area is generally small in comparison with the number of picture elements needed to form a pleasing image of the magnetic field pattern in that area. A procedure is needed to effectively increase the number of data. Program MAGP, therefore, is basically a linear, two-dimensional interpolation routine to expand the magnetic data file.

Program PICT divides the total range of magnetic field values in the expanded file into a discrete number of levels, assigns a color to each level, and produces a level-sliced color picture of the magnetic field values. 


\subsection{SURVEYS AND RESULTS}

\subsection{INITIAL ACTIONS AND SITE PREPARATION}

The geophysical surveys described in this section were performed during the period September 20-26, 1979. Three site locations for waste detection measurements within the RWMC were specified by EG\&G. Our initial efforts were focused on acquiring radar, magnetometer, and metal detector data at those sites.

At each site we defined a rectangular survey area by marking the corners with wooden stakes. Then we placed ropes between the stakes on two opposing ends of the rectangular area. The ropes had footage marks at, 5-foot $(1.52 \mathrm{~m})$ intervals. While making measurements with the radar, magnetometer, or metal detector, we ran additional marked ropes the length of the survey area (between the end ropes) to define survey tracks. In effect, this procedure established a grid system across each survey area.

The fourth site was located outside the east perimeter fence of the RWMC. The objective at this site was to investigate the feasibility of measuring the depth to the basalt bedrock by means of ground-penetrating radar. Measurements at this site were limited to three parallel tracks spaced $5 \mathrm{ft}(1.52 \mathrm{~m})$ apart.

\subsection{DATA PROCESSING AND RADAR CALIBRATION}

All of the radar and magnetic data acquired at the three sites within the RWMC were processed in a manner consistent with the procedure diagrammed in Figure 9. The following discussion includes photographs of representative radar profiles for each site which illustrate both processed and unprocessed data.

In order to determine the depths of subsurface radar reflectors, it is necessary to know the propagation velocity of the radar signal in the ground and to calibrate the radar in terms of signal travel time. In our radar data processing, we used a value of $1.5\left(10^{8}\right) \mathrm{m} / \mathrm{sec}$ for the propagation velocity. This value is at the low end of a range of estimates derived from 
three sources. First, Grace et al. (1) quote a value of $1.45\left(10^{8}\right) \mathrm{m} / \mathrm{sec}$. Second, our measurements of hyperbolic reflection patterns gave values of 1.6 to $1.7\left(10^{8}\right) \mathrm{m} / \mathrm{sec}$. Third, our basalt reflection data described in $\mathrm{Sec}-$ tion 5.6 are consistent with values in the range 1.5 to $1.6\left(10^{8}\right) \mathrm{m} / \mathrm{sec}$. Precise values of the propagation velocity could not be derived from our data because we obtained very few good, classical, hyperbolic reflection patterns or good reflections from objects at known depths. Some variation in the radar propagation velocity is to be expected because of variations in soil characteristics from place to place within the RWMC.

For travel time calibration, we first determined the optimum radar control settings for a given area or survey. Then using those settings, we recorded air-path reflections of the radar signal from the side of our computer truck or a similar large object. Knowing the velocity of the radar signal in air and the distance between the radar antenna and the reflector, it is easy to calculate the travel time of the reflected signal. Figure 12 is an example of a radar ping reflected from the computer truck. The radar-to-truck distance was $30 \mathrm{ft}(9.1 \mathrm{~m})$ and the travel time was $61.0 \mathrm{nsec}$, giving a total ping length of $137 \mathrm{nsec}$. The strong oscillations near the top of the ping clearly illustrate the ringing that is always present in the transmitted signal. Those oscillations are also present in the reflected signal. They are a major source of confusion in the interpretation of radar reflection profiles when the distribution of reflecting objects is dense or complex. In particular, the ringing of the transmitted signal tends to mask nearsurface reflections.

\subsection{SITE 1}

This is the Trench 58 test site described by Grace, et al. (1) They buried a steel barrel, a wooden pallet, and three metal pipes in the trench in order to test their radar equipment in a controlled situation. Information on exact locations of the buried objects was not available for our tests at the site, however. 


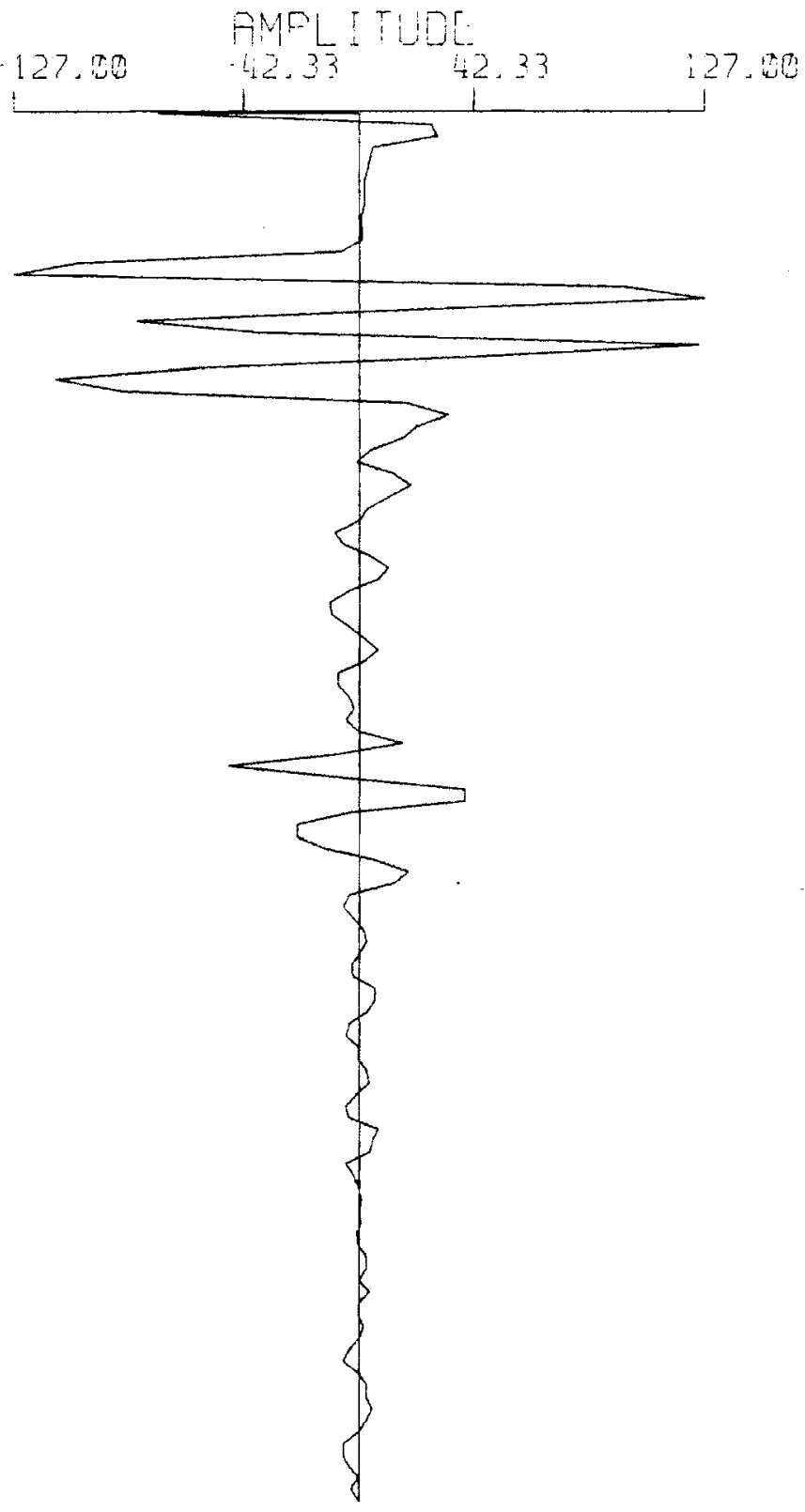

FIGURE 12. Radar Ping Reflected from the Computer Truck. 
Figure 13 is a diagram of the test site. Our measurements were all referenced to the superimposed coordinate system which was marked by stakes and ropes as described above. The results of a metal detector survey, conducted in an attempt to locate the buried metal objects, are also shown in the figure. A large mass of metallic materials is buried in an apparent trench under the road adjacent to Trench 58. The edges of the mass are shown schematically since the metal detector is not capable of precisely defining the edges of a large buried mass. The circled crosses indicate locations where weaker, isolated, metal detector responses were obtained. Those locations form a pattern which is aligned with the trench. Presumably, they correspond to the buried metal objects. It is not clear why the pipes should be detected as point objects, although our metal detectors do not respond optimally to pipe-shaped objects. The objects in the crosshatched part of the trench were relatively strong, suggesting that they were due to the barrel.

Figure 14 shows magnetic contours superimposed on the diagram of Figure 13. They confirm the presence of a large metallic mass under the road and show that it contains a substantial quantity of steel. The magnetic contours in the remainder of the test area give no indication of other large buried ferromagnetic objects, but they do show a weak positive peak at the presumed location of the barrel (coordinates 10 west, 10 south), and another small peak at approximately 40 west, 10 south. (The prominent peak at 50 south is due to an error in data transcription.) The magnetic data shown in the figure are the second derivative of the measured data continued upward to a height of $9 \mathrm{ft}(2.7 \mathrm{~m})$. The height of the measurement plane was $4 \mathrm{ft}$ $(1.2 \mathrm{~m})$.

Figure 15 is a level sliced color map of the magnetic data. The red and blue colors correspond respectively to high and low magnetic values. Contour lines are superimposed to give a quantitative meaning to the colors.

The survey tracks for our radar tests were aligned north-south because of the open trench at the east end of the site. This was not the optimum track direction for detecting the buried pipes, which are oriented north-south $(1)$ 


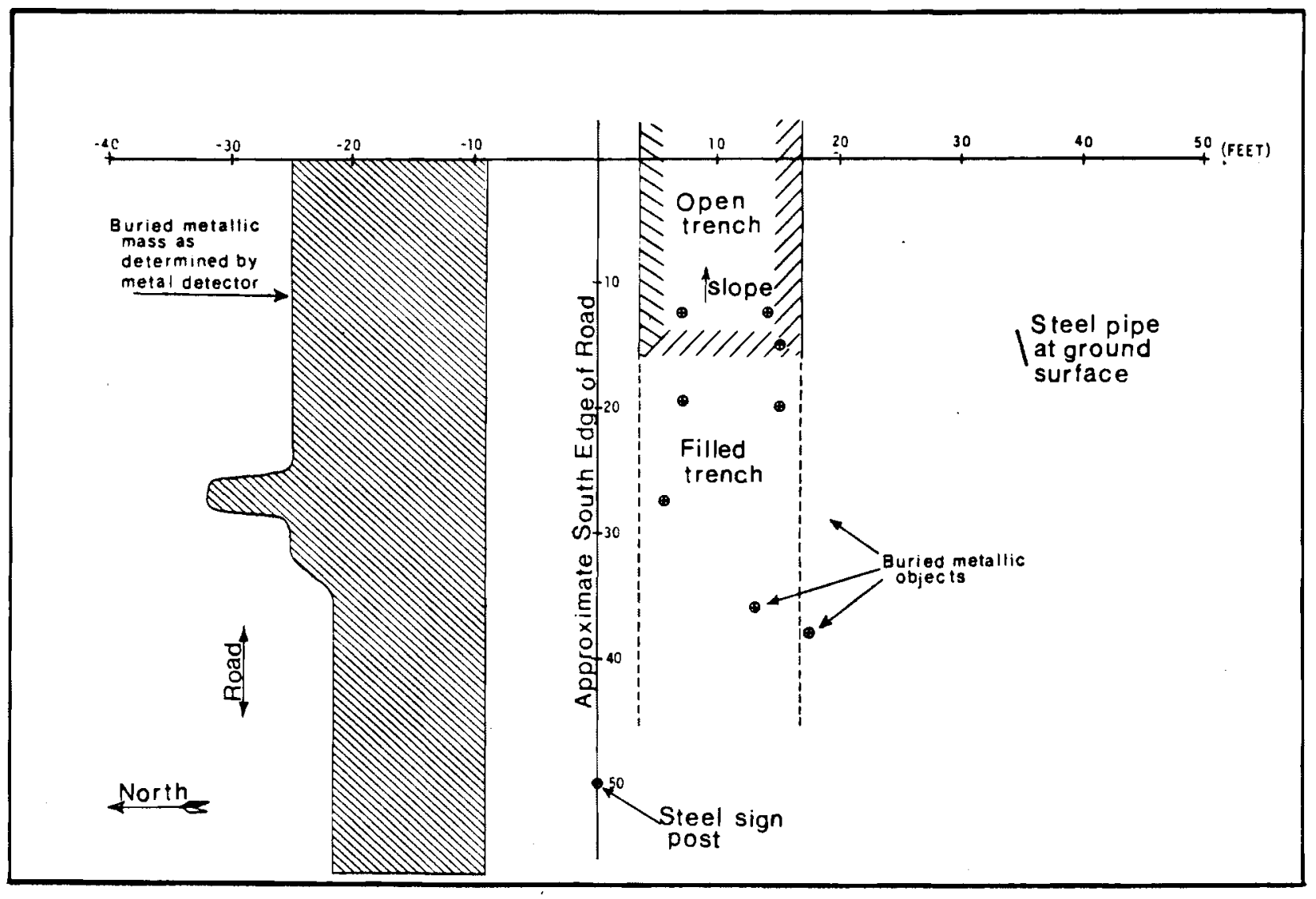

FIGURE 13. Diagram of Site 1 Showing Metal Detector Survey Results. 


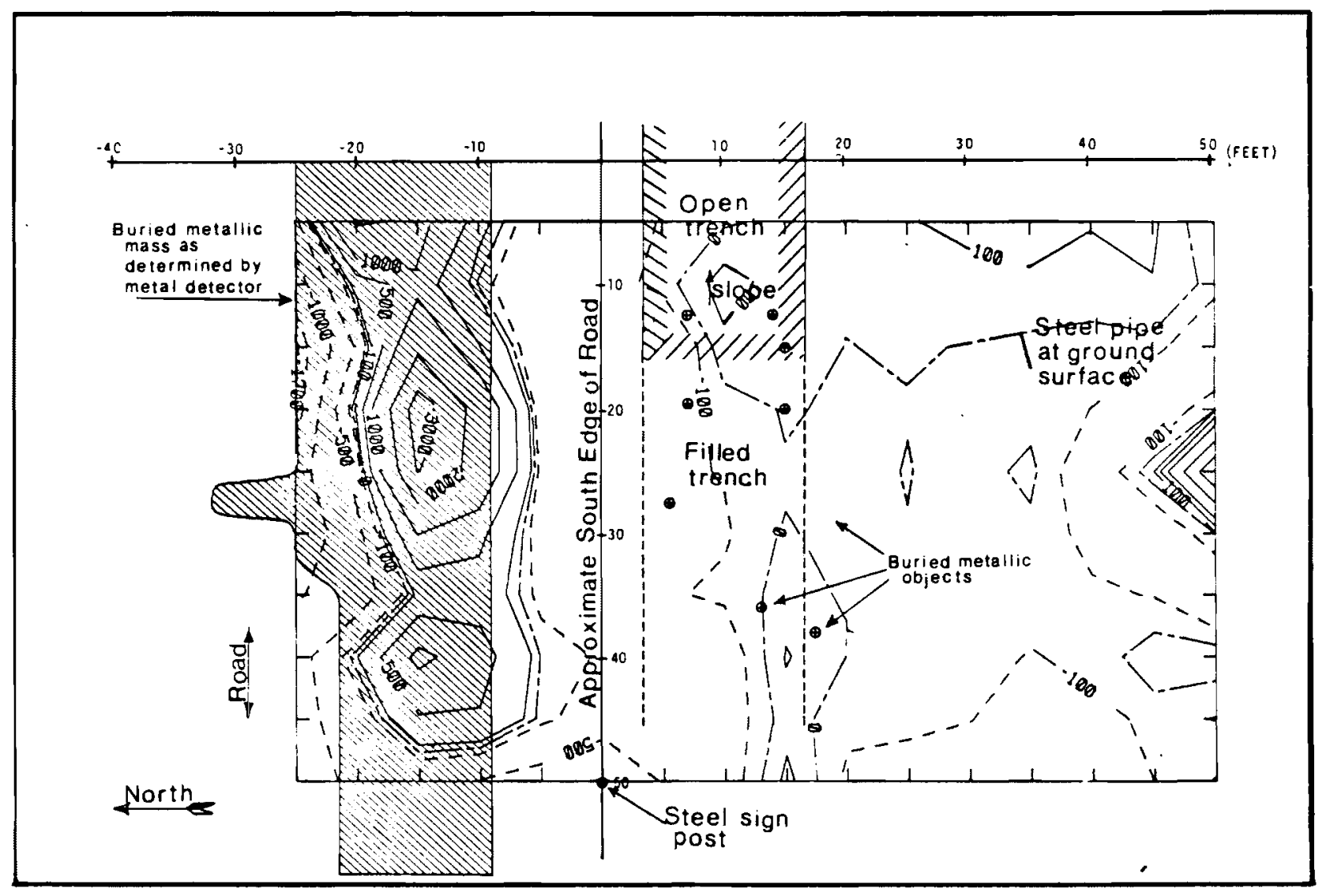

FIGURE 14. Diagram of Site 1 Showing Metal Detector and Magnetometer Survey Results. 


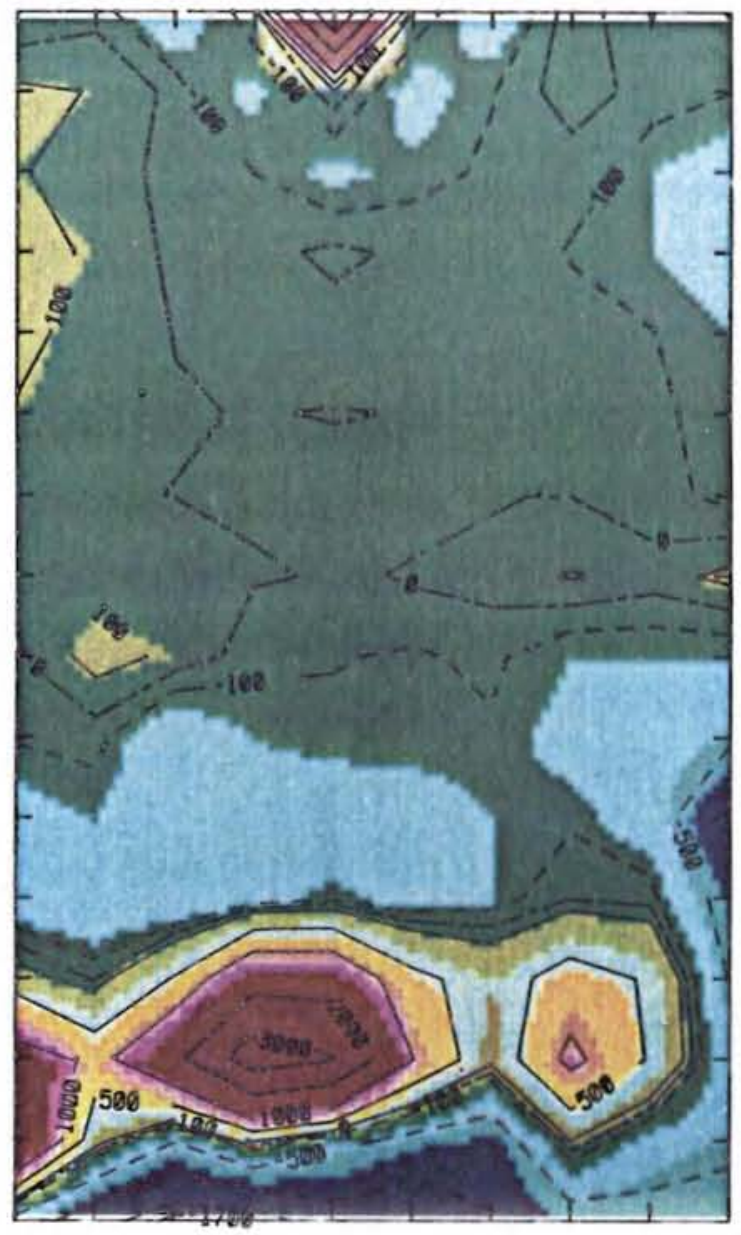

$\mid$

FIGURE 15. Level Siiced Color Map of Magnetic Data at Site 1. 
Consequently, they are not discernable in the radar data shown in Figures 16 and 17. Figure 16 shows two representative radar profiles (two tracks). Each group of three images (left and right) shows three versions of one profile, just as in Figure 10 . Figure 17 is a level sliced map view of the radar data (see discussion of program SLICE, Section 4.1.3) with the site diagram superimposed on it. In this figure, and in similar figures below, the red and yellow colors correspond to strong radar reflections. The blue shades indicate the absence of reflections.

Figures 16 and 17 both clearly show reflections from the large mass under the road. Various other reflections are scattered throughout the survey area. It is difficult to know whether or not one of these corresponds to the barrel. The wooden pallet cannot be identified in either the profiles or the map views. Scattered reflections that cannot be attributed to buried objects are probably due to variations in the texture or composition of the soil. These variations can occur during the natural deposition of the sediments, or they can result from trench excavation and backfilling.

In summary, the combination of metal detector, magnetometer, and radar data effectively define a portion of a filled trench under the road parallel to Trench 58. The metallic objects buried by EG\&G at this site were probably detected by the metal detector and magnetometer, but were not identifiable in the radar records. Difficulty in recognizing a reflection from the barrel is probably due to clutter from nearby random scatterers. The barrel would normally be an easily recognizable radar target. 


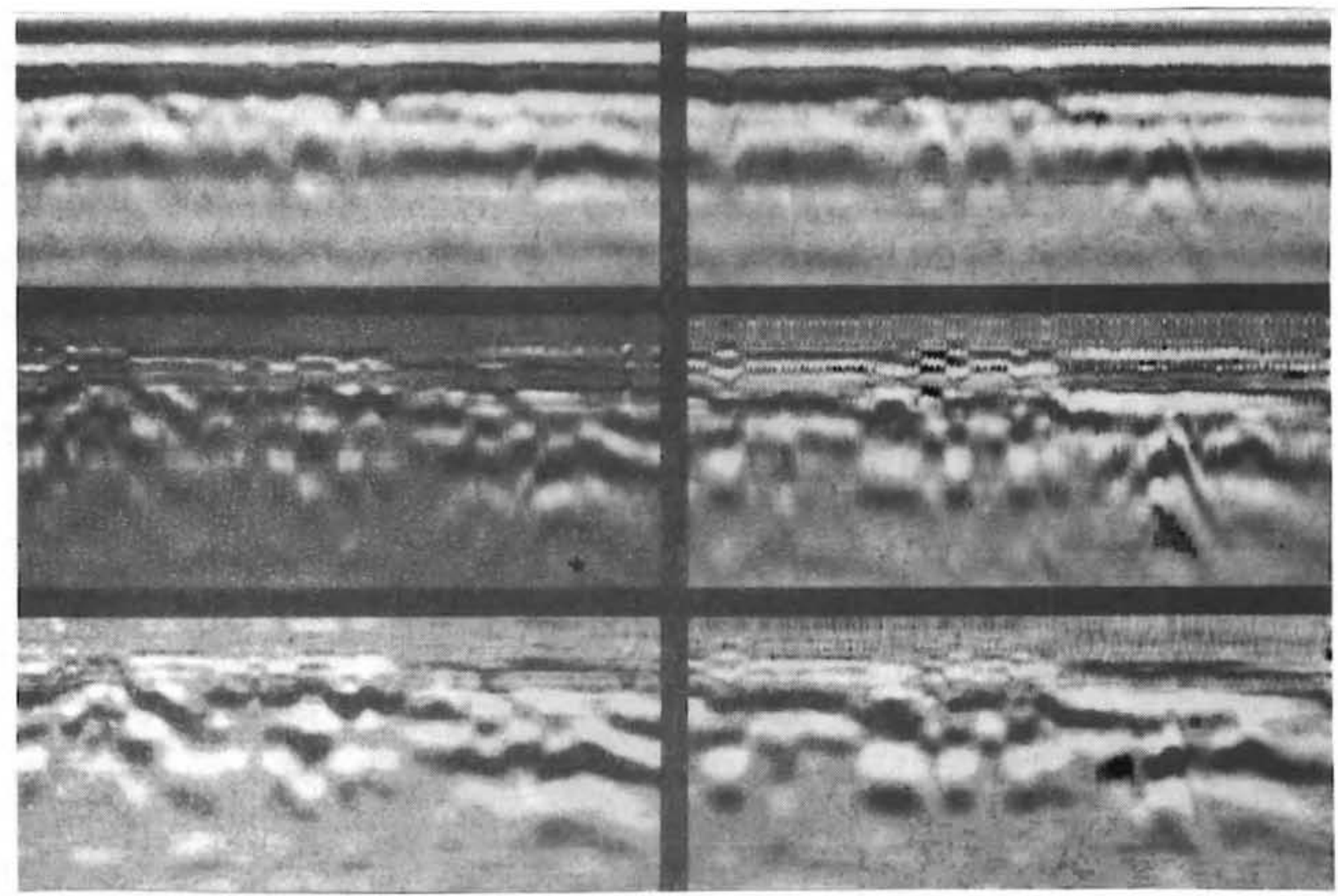

FIGURE 16. Two Radar Profiles from Site 1. From Top to Bottom of Each Side: Unprocessed, Processed by REMVH, and Processed by REMVH and HYPER. Maximum iepth is Approximately $10 \mathrm{ft}(3 \mathrm{~m})$. 


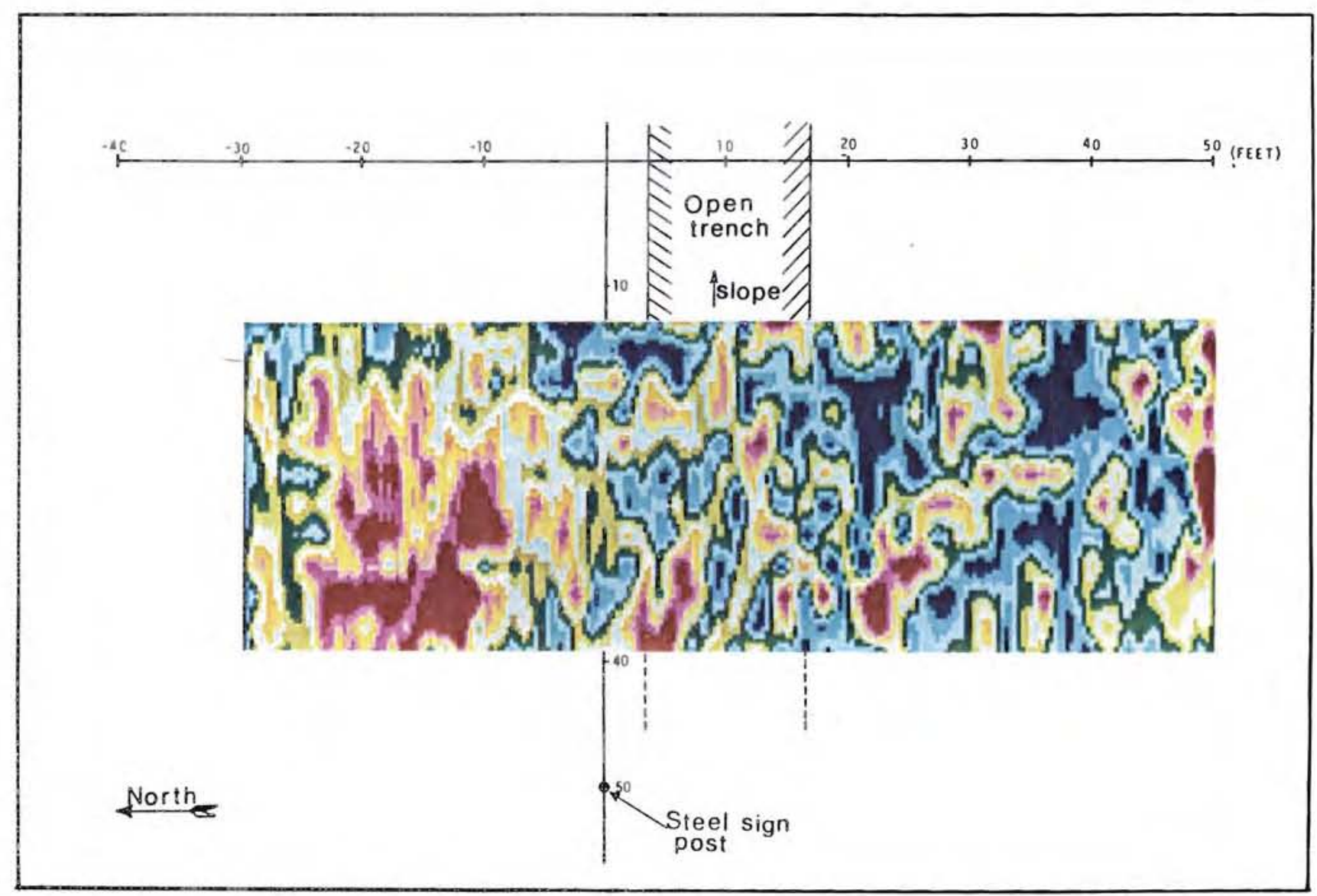

FIGURE 17. Level Sliced Color Map View of Radar Data from Site 1. 


\subsection{SITE 2}

This site was located in the northwest corner of the RWMC in the area of Trenches 5, 7, and 9. It was approximately $200 \mathrm{ft}(61 \mathrm{~m})$ north of site 1 . The trenches at this location are oriented east-west and are covered with a clay cap. Figure 18 shows the layout and location of this site.

The cross-hatching in Figure 18 shows a broad distribution of buried metallic materials as determined by the metal detector. The small area out7 ined inside the larger cross-hatched area gave a weak-to-zero metal detector response. Metallic wastes may be either absent or more deeply buried at that location. This interpretation is supported by the magnetic contours shown in Figures 19 and 20. The contours indicate linear concentrations of buried steel materials in four east-west zones located approximately at the following north-south coordinates: $\leqslant-10,0-20,30-40$, and 55-70.

Radar data for this site are shown in Figures 21 and 22. The profiles show strong reflections in east-west zones at approximately 0-20, 25-40, and 50-70 (the radar measurements did not extend into the area of negative northsouth coordinates). The middle zone is the least well expressed of the three zones shown in the radar profiles and is not evident in the map view (Figure 22).

In summary, the metal detector measurements suggest that buried metallic waste materials are distributed throughout a wide zone trending approximately east-west across the survey area. The radar and magnetic data show a more detailed pattern of high and low waste concentrations within that broad zone. They also show a zone of waste at 50-70 north that was not detected by the metal detector. The lack of a metal detector response and the relatively low magnetic values in that zone imply that it contains a smaller quantity of steel and other metals than the other zones.

\subsection{SITE 3}

This site was located approximately $1000 \mathrm{ft}(305 \mathrm{~m}$ ) east of Site 1 . It was approximately $100 \mathrm{ft}(30.5 \mathrm{~m})$ west of a large open pit. Two rectangular survey areas ( $A$ and $B$ ) were layed out at this site as shown in Figure 23. According to information given to us on site by EG\&G, the dashed lines in the figure mark the locations of rows of buried boxes containing waste materials. 


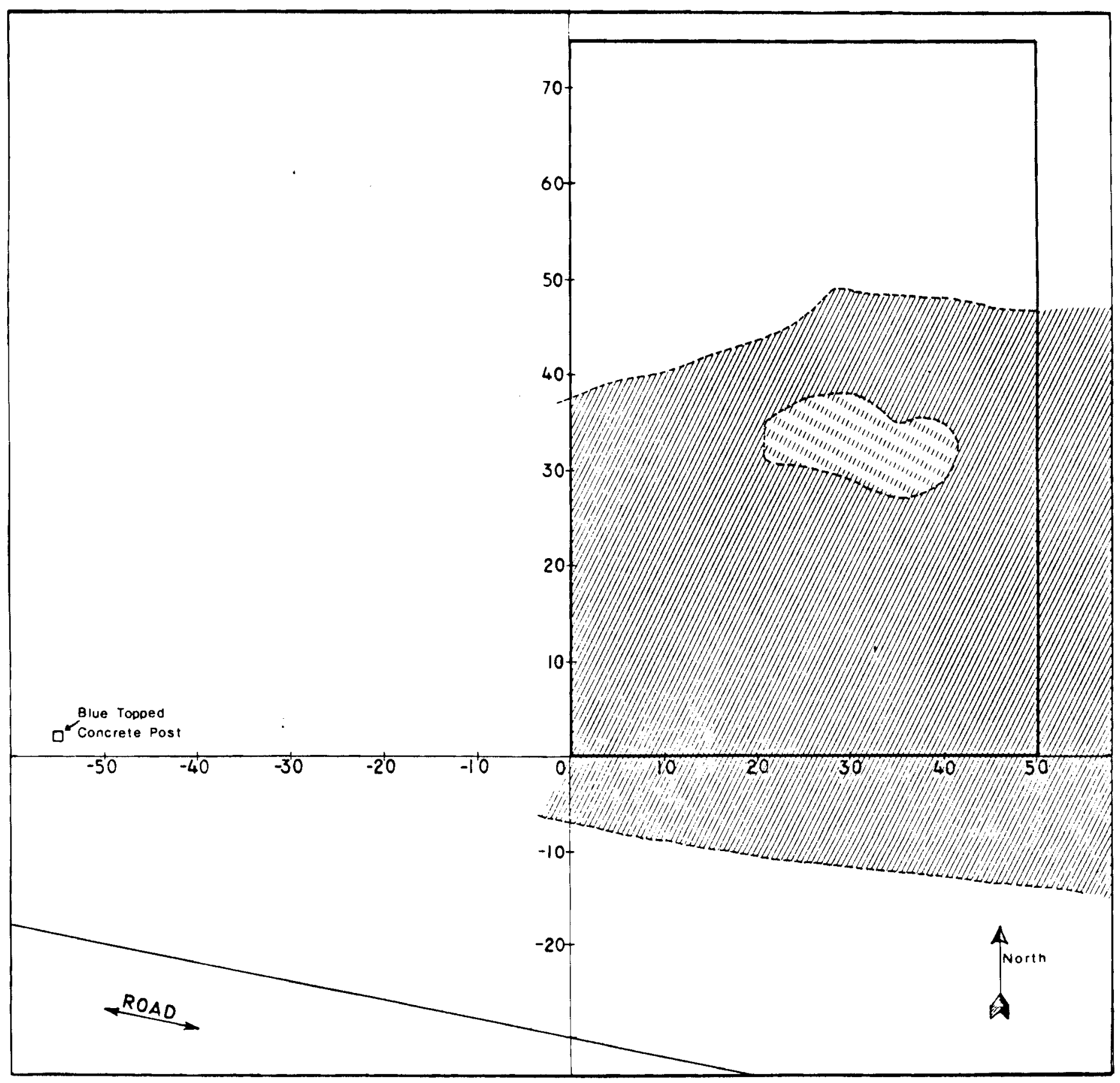

FIGURE 18. Diagram of Site 2 Showing Metal Detector Survey Results. 


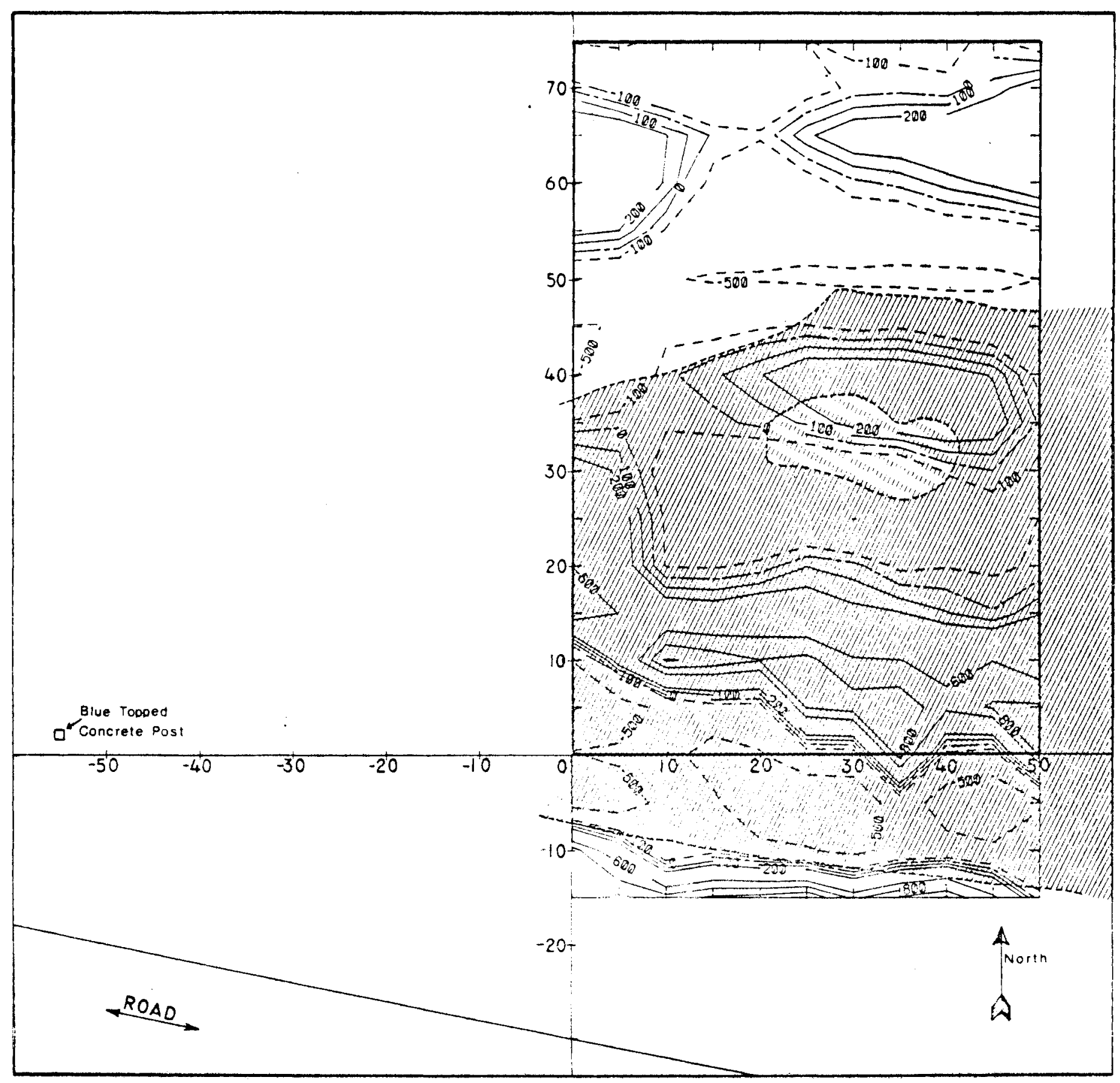

FIGURE 19. Diagram of Site 2 Showing Metal Detector and Magnetometer Survey Results. 


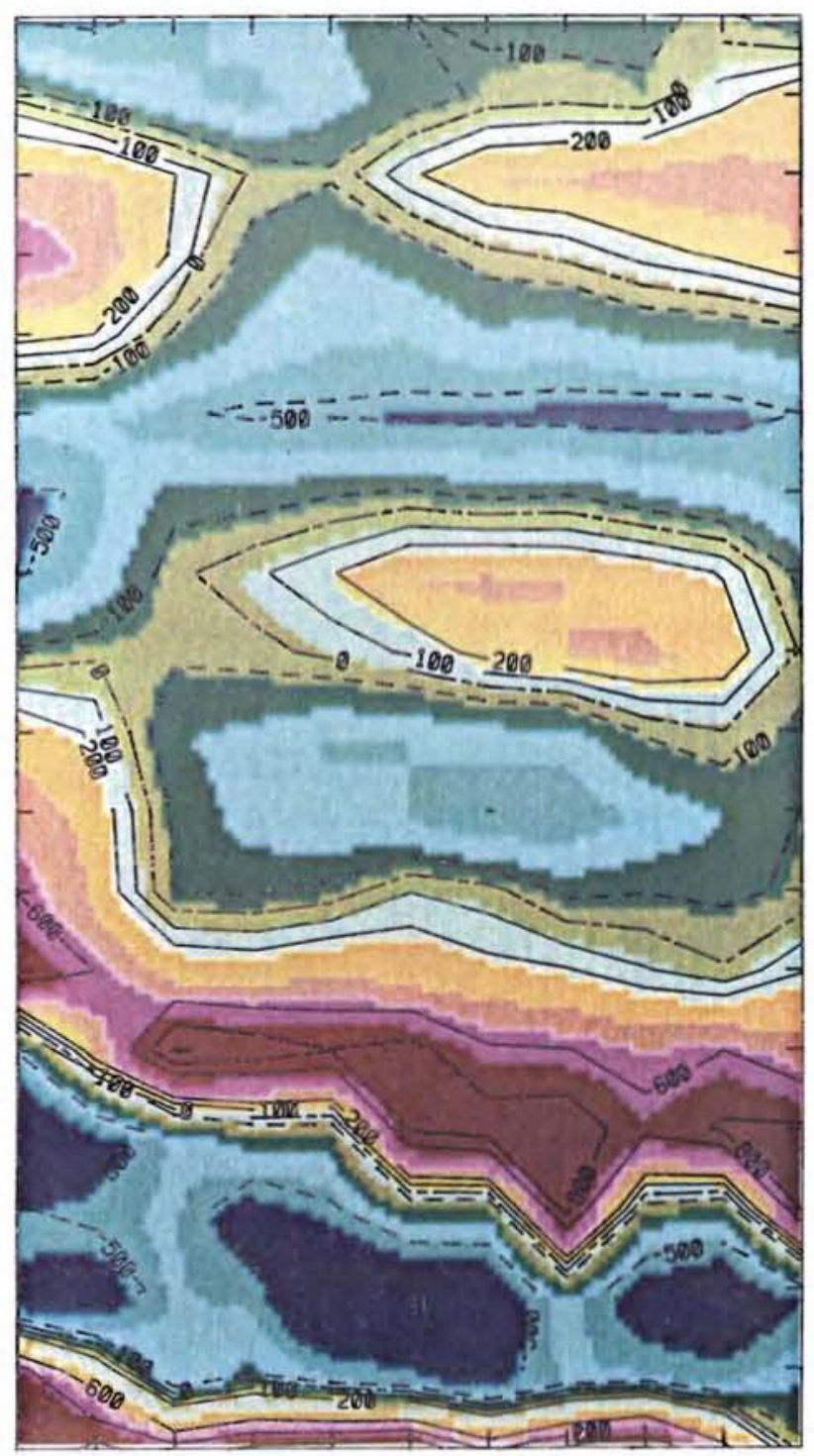

FIGURE 20. Level Sliced Color Map of Magnetic Data at Site 2. 


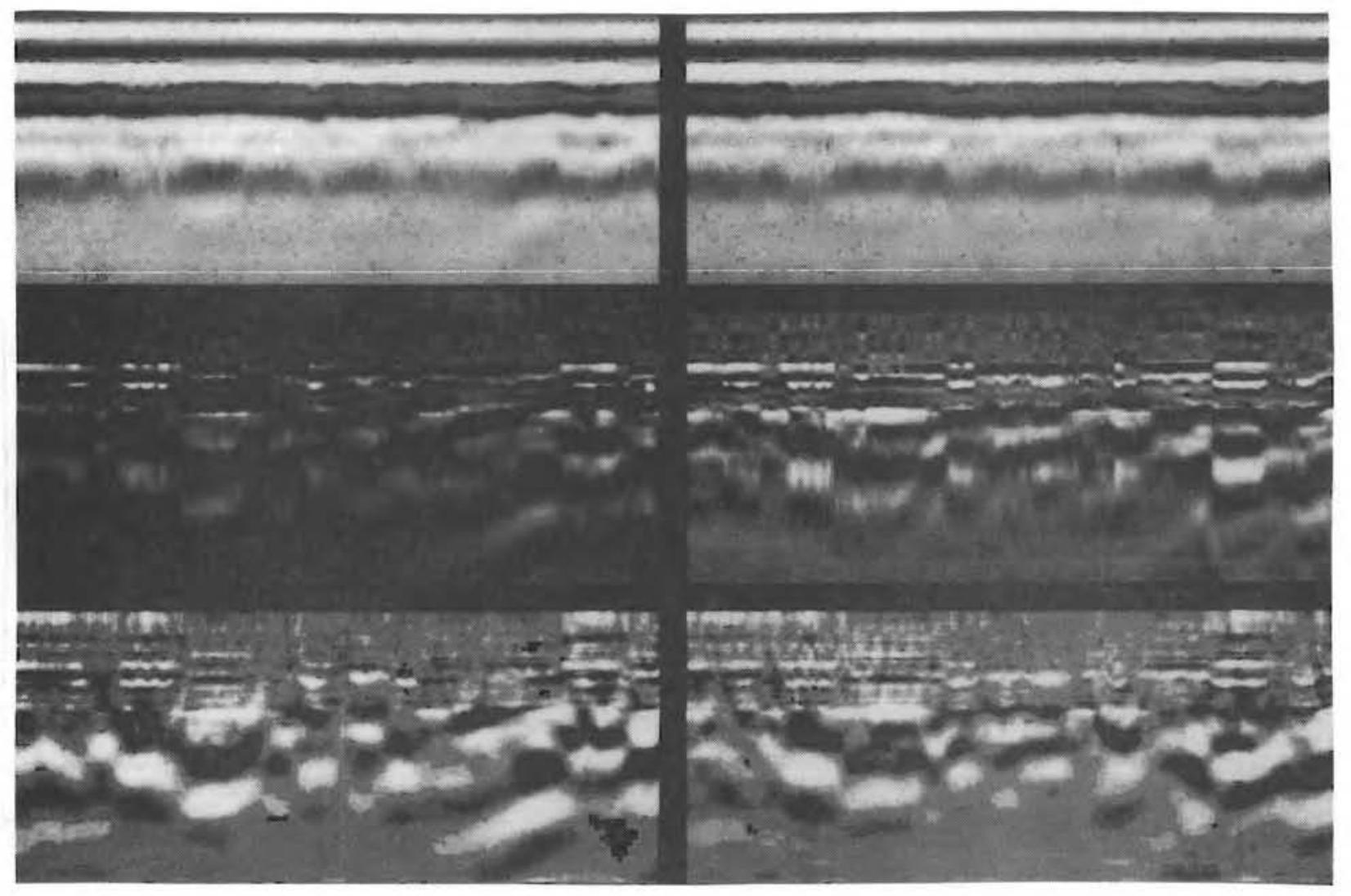

FIGURE 21. Two Radar Profiles from Site 2. From Top to Bottom of Each Side: Unprocessed, Processed by REMVH, and Processed by REMVH and HYPER. Maximum Depth is Approximately $10 \mathrm{ft}(3 \mathrm{~m})$. 


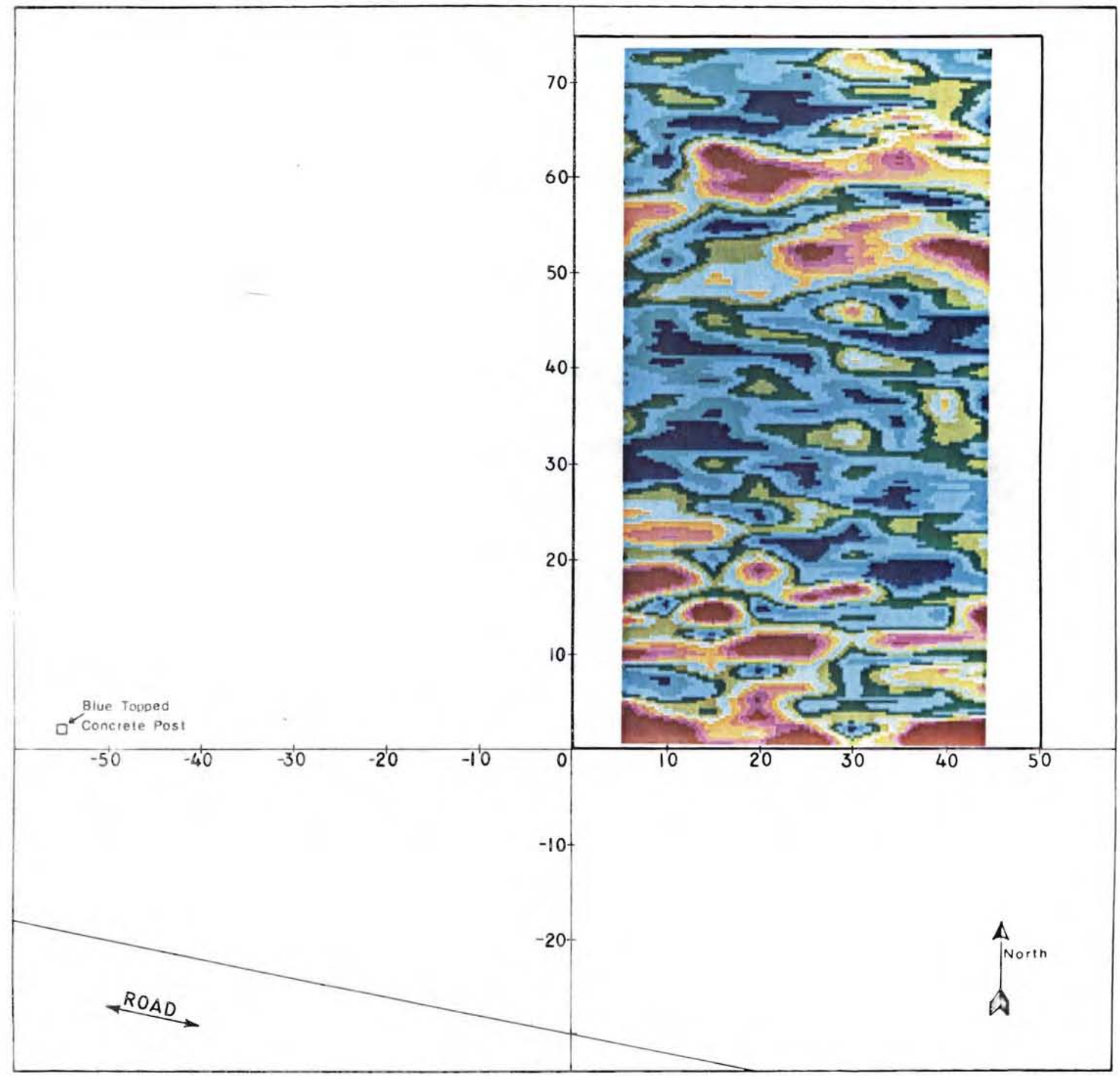

FIGURE 22. Level Sliced Color Map View of Radar Data from Site 2. 


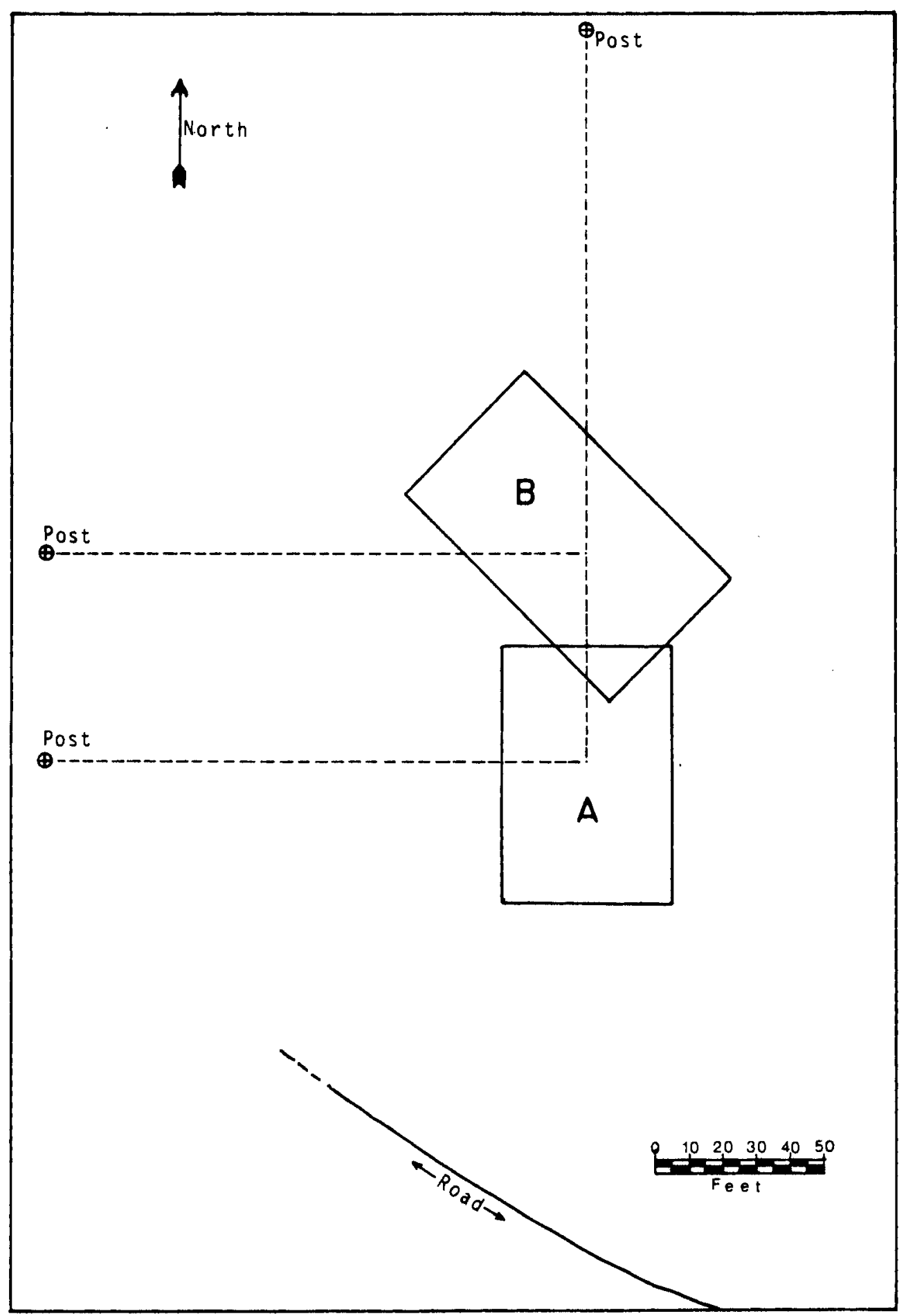

FIGURE 23. Diagram of Site 3. 
Figure 24 shows the results of metal detector and magnetometer surveys in Area $A$. The magnetometer measurements were extended $5 \mathrm{ft}(1.5 \mathrm{~m})$ beyond the east side of the area. The metal detector signal was very strong in the cross-hatched zone, indicating a large buried mass of metallic materials. That mass actually extends approximately $80 \mathrm{ft}(24.4 \mathrm{~m})$ farther to the east than shown in the figure. It was traceable to that distance by both the metal detector and the magnetometer. The magnetic contours (Figures 24 and 25) confirm the presence of a metallic mass in the cross-hatched zone. They also suggest that ferromagnetic materials are buried in or near the northwest and southwest corners of the survey area. There may be a continuous distribution of material between the southwest corner and the cross-hatched zone.

The radar data from Area $A$ are illustrated in Figures 26 and 27 . The radar profiles show strong reflections over much of the survey area with exceptionally flat, horizontal reflections at a depth of approximately $2.5 \mathrm{ft}$ (.8 $\mathrm{m}$ ) at the north and south ends. Similar reflections occurred at other sites. A good example is evident in Figure 16 which shows a flat reflection above a strong hyperbolic reflection pattern. Without additional information, it is difficult to determine the significance of these flat reflections. They may correspond to trenches--possibly to the tops of wooden boxes--or to spaces between trenches. The available evidence is confusing. The flat pattern at Site 1 occurs over a substantial mass of apparent waste material, whereas the (assumed) undisturbed ground at the south end of that site produced relatively complex reflections. On the other hand, the radar reflections from the buried wastes indicated in Figure 24 are also strong, but complex (see Figure 26, right side).

We did not perform a metal detector survey in Area B. However, we did perform a magnetometer survey as shown in Figure 28 . The magnetic patterns clearly indicate a linear, east-west trending distribution of ferrous materials, but the relatively small amplitude of the magnetic anomaly suggests that ferrous objects are mixed with other types of waste materials. The curvature of the contour lines in the south quadrant of the survey area conforms to the contour pattern in the northwest corner of Area $A$. The data suggest the presence of a broad east-west trench with a concentration of ferrous materials along its north edge. 


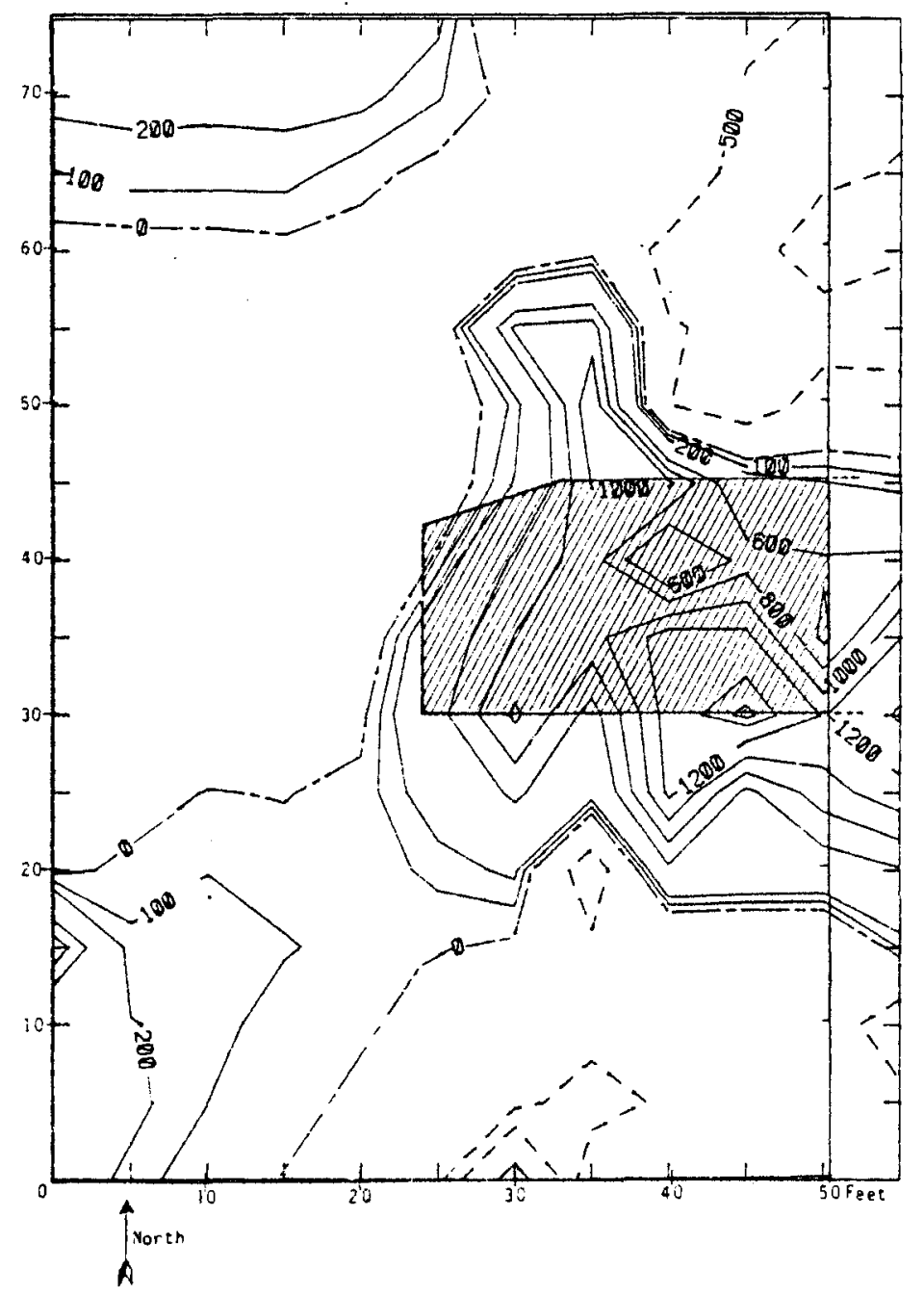

FIGURE 24. Meta] Detector and Magnetometer Survey Results in Area A, Site 3. 


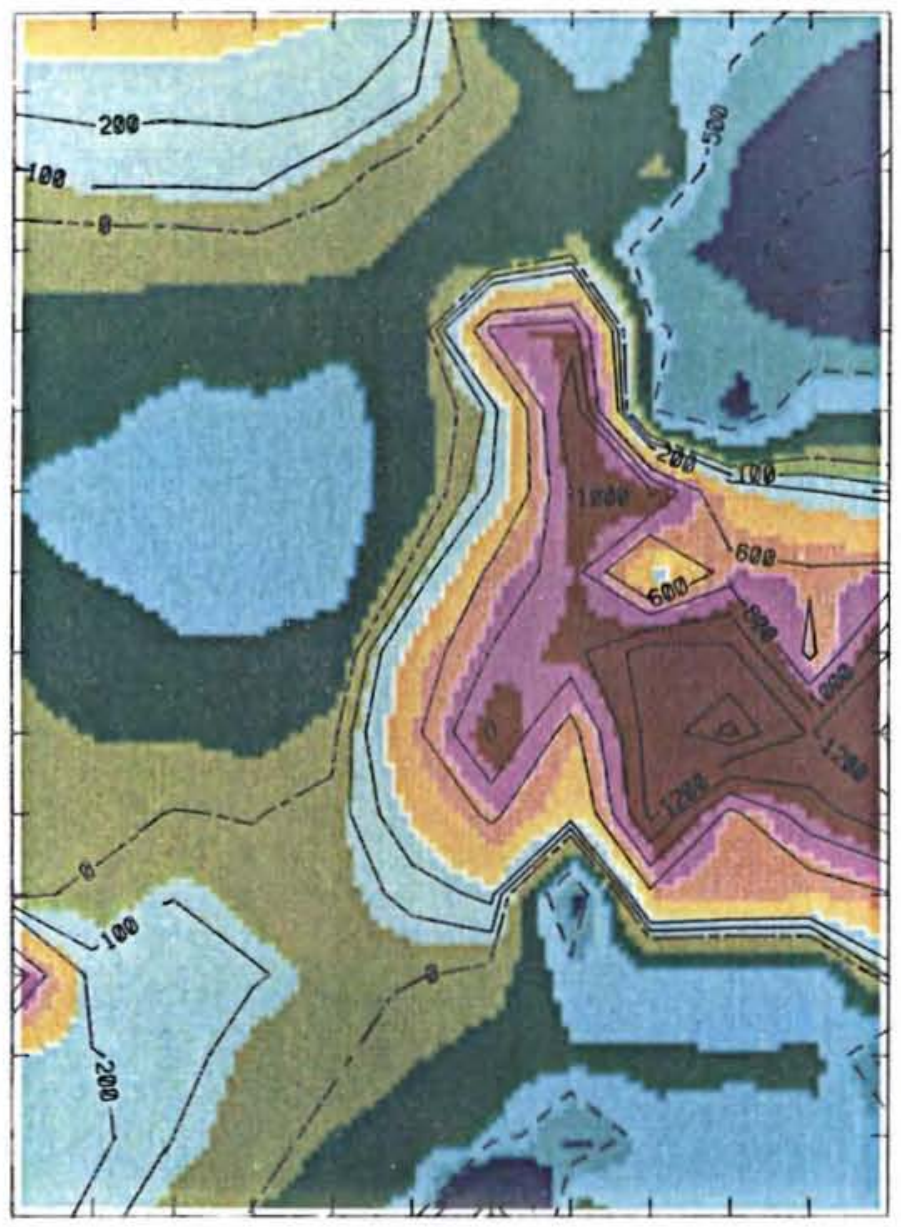

FIGURE 25. Level Sliced Color Map of Magnetic Data in Area A. Site 3. 


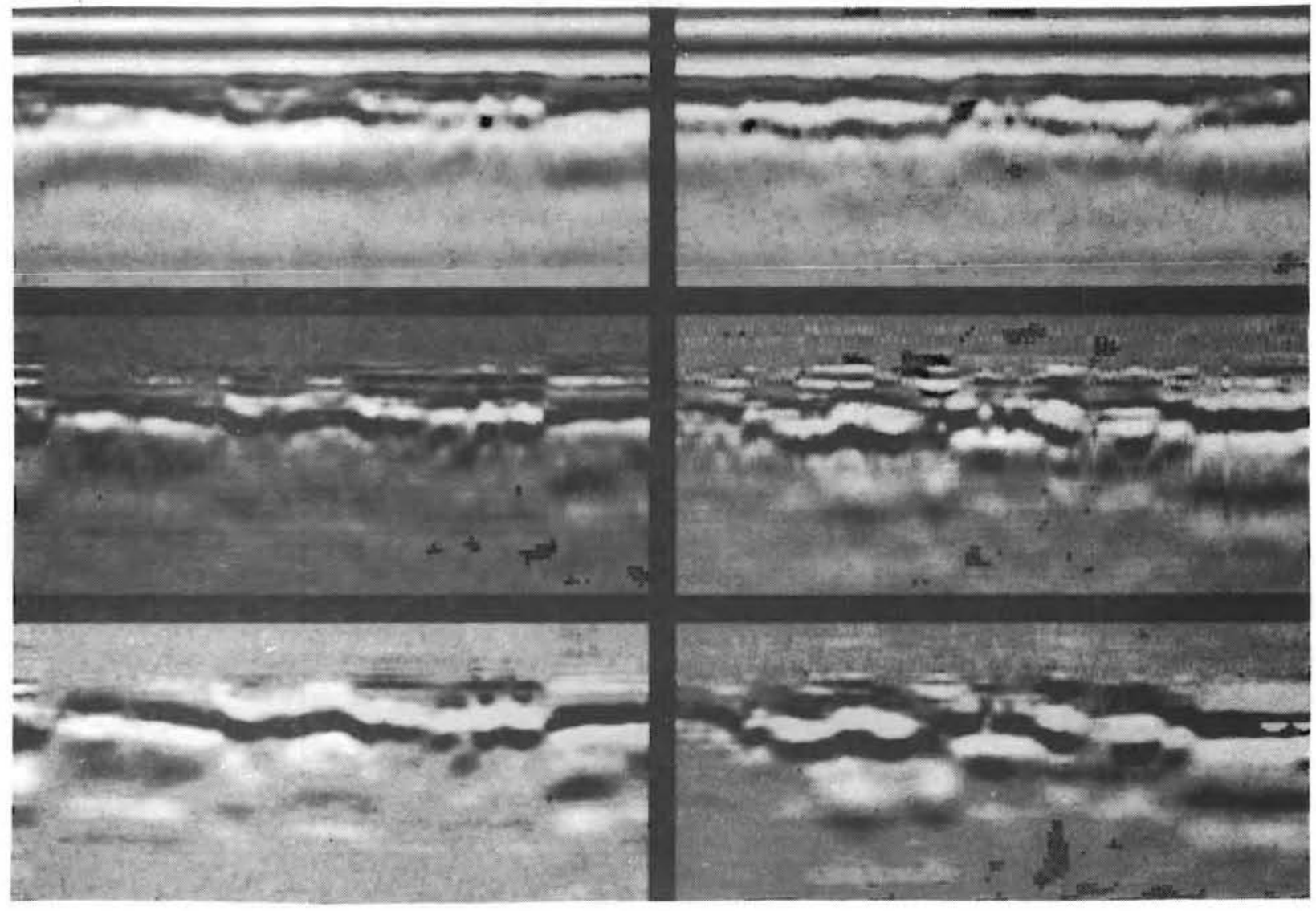

FIGURE 26. Two Radar Profiles from Area A, Site 3. From Top to Bottom of Each Side: Unprocessed, Processed by REMVH, and Processed by REMVH and HYPER. Maximum Depth is Approximately $10 \mathrm{ft}(3 \mathrm{~m})$. 


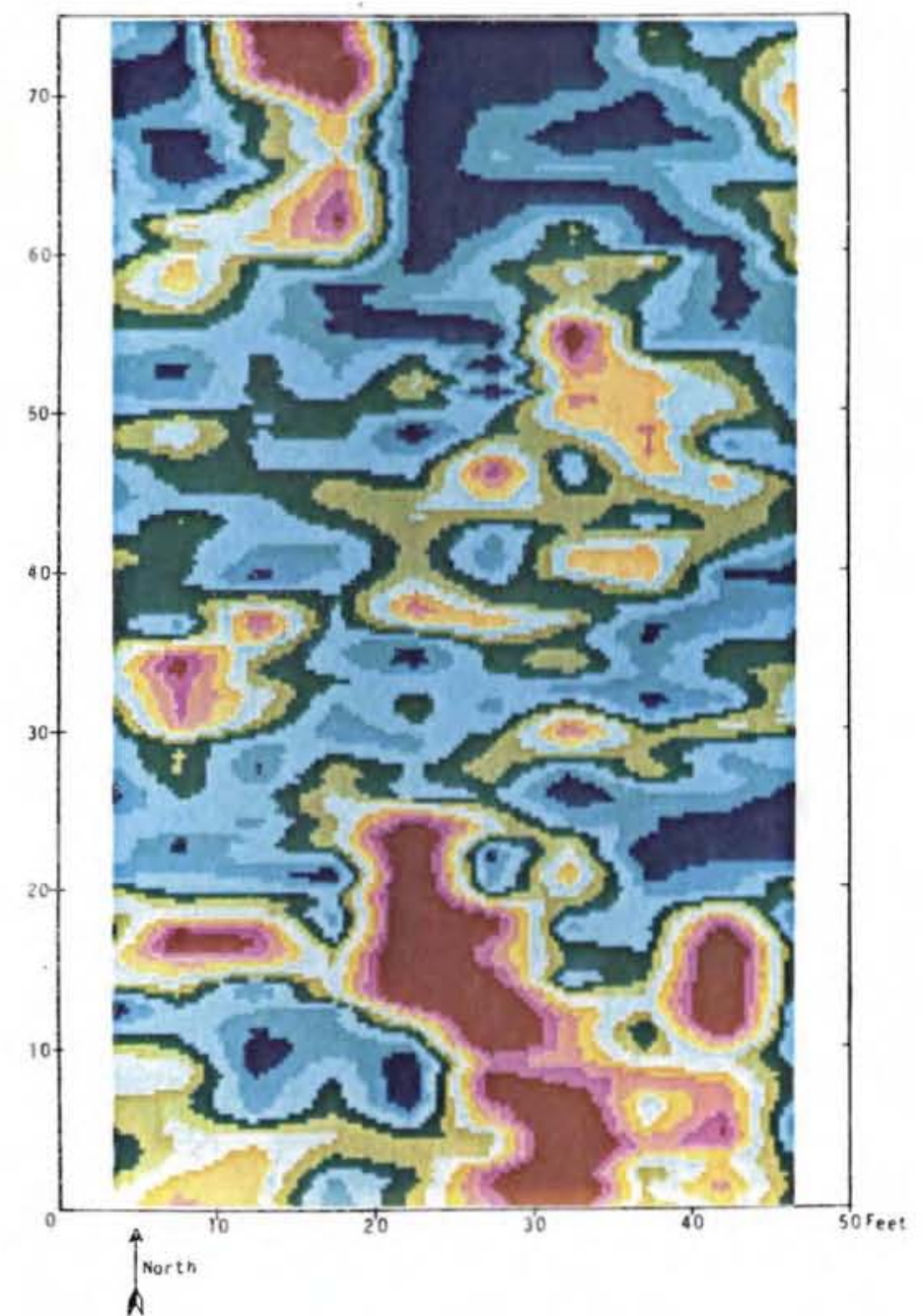

FIGURE 27. Level Sliced Color Map View of Radar Data from Area A, Site 3. 


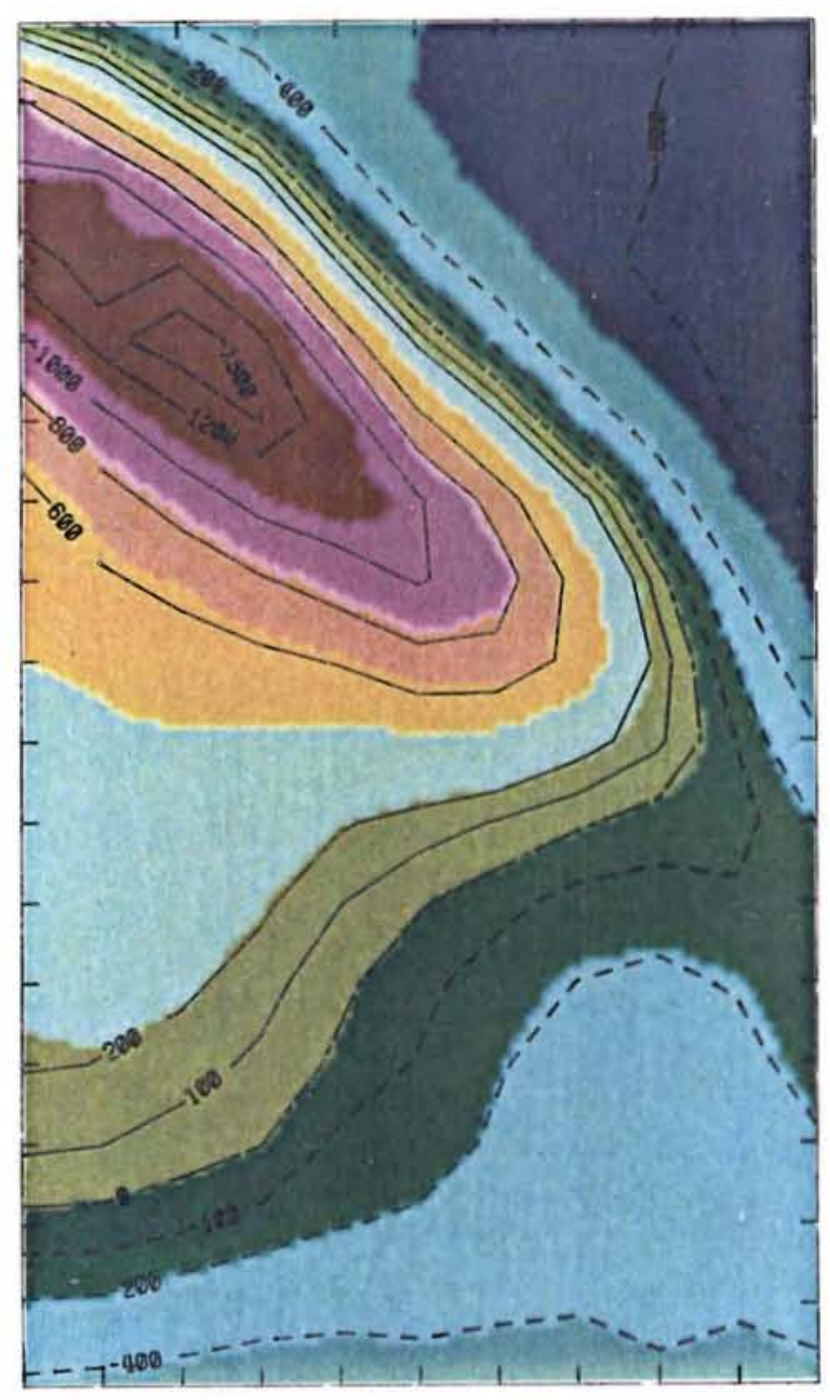

FIGURE 28. Level Sliced Color Map of Magnetic Data in Area B, Site 3 . 
The radar data from Area B are illustrated in Figures 29 and 30. Perhaps the most striking aspect of these data is that the reflections are weakest where the magnetic anomaly in Figure 28 is strongest. This result is clearly shown in both figures. However, the linearity of the blue pattern and its alignment with the magnetic pattern suggest a correlation between the waste materials and the radar signals. Flat reflections also occur at the southeast end of this survey area.

In summary, the metal detector and magnetometer data from Areas $A$ and $B$ clearly outline two linear distributions of waste materials. Their approximate alignment with the east-west dashed 1 ines in Figure 23 conforms in part to the expected result. It is not clear, however, where the waste deposits begin and end or whether they consist entirely of metallic materials. The magnetic data in Area B and the northwest corner of Area $A$ suggest the presence of an east-west trench considerably wider than the prominent anomaly in Area B. This may be indicated by the radar data as well if the flat reflections are derived from areas outside the trenches. These surveys demonstrate the need for definitive ground truth which will allow criteria to be established for the interpretation of radar data.

\subsection{SITE 4}

This test site was located just outside the perimeter fence on the east side of the RWMC. Figure 31 shows the location and orientation of the site relative to the RWMC fence and a previously drilled test well.

Our purpose for collecting data at this site was to assess the feasibility of measuring the depth to the basalt bedrock by means of ground-penetrating radar. The selected site was appropriate for three reasons: 1) it was accessible, 2) the area had been cleared of sagebrush, and 3) the depth to basalt is known at the test well. According to available well log data, the depth to basalt at the well is approximately 1 meter. Figure 32 is a radar profile along the track closest to the well. As in previous figures showing radar profiles, the horizontal dimension corresponds to distance along the survey track. The vertical dimension corresponds to the 2-way travel time of the radar signal and is, therefore, proportion to depth. Figure 33 shows 


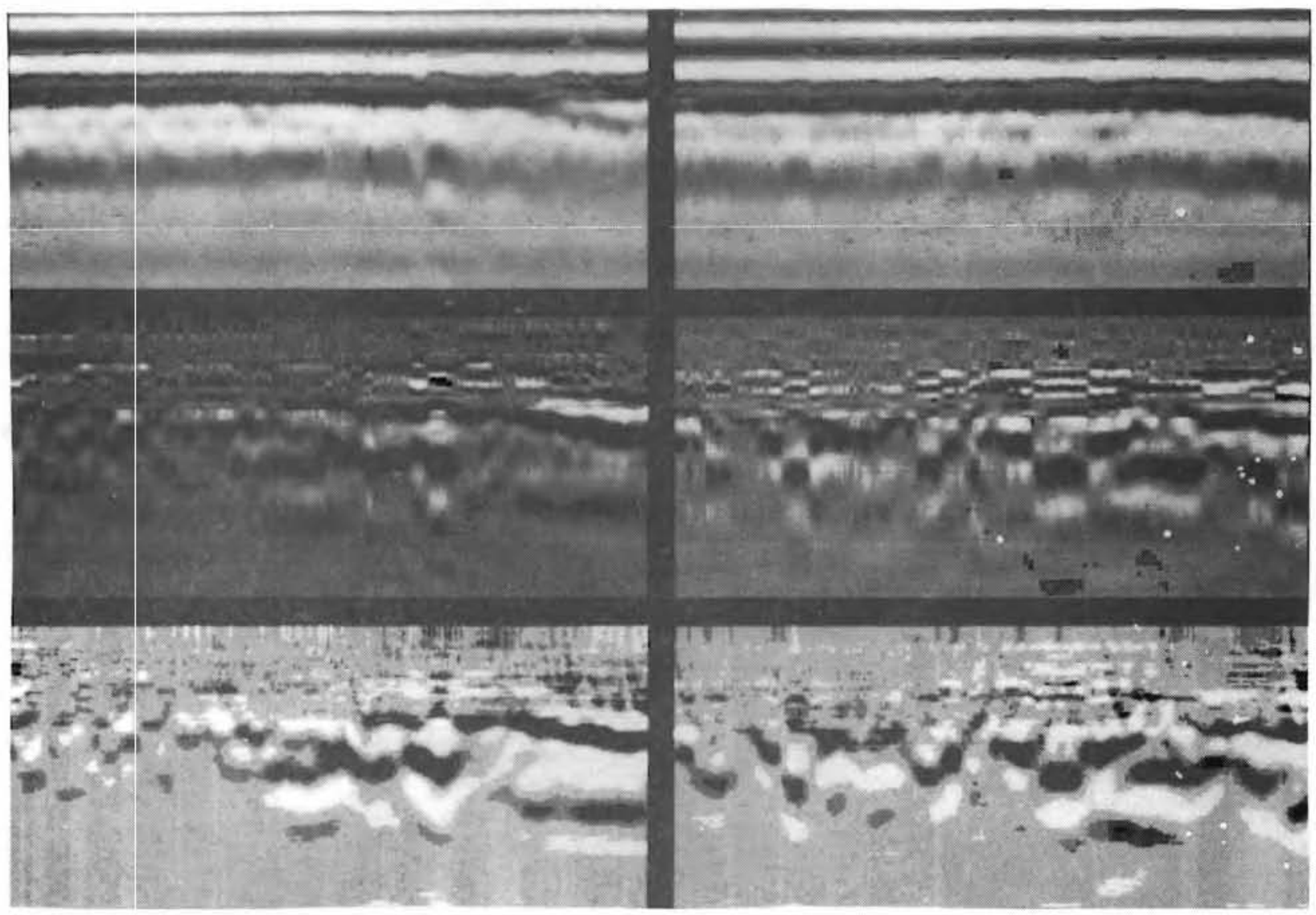

FIGURE 29. Two Radar Profiles from Area B, Site 3. From Top to Bottom of Each Side: Unprocessed, Processed by REMVH, and Processed by REMVH and HYPER. Maxinium Depth is Approximately $10 \mathrm{ft}(3 \mathrm{~m})$. 


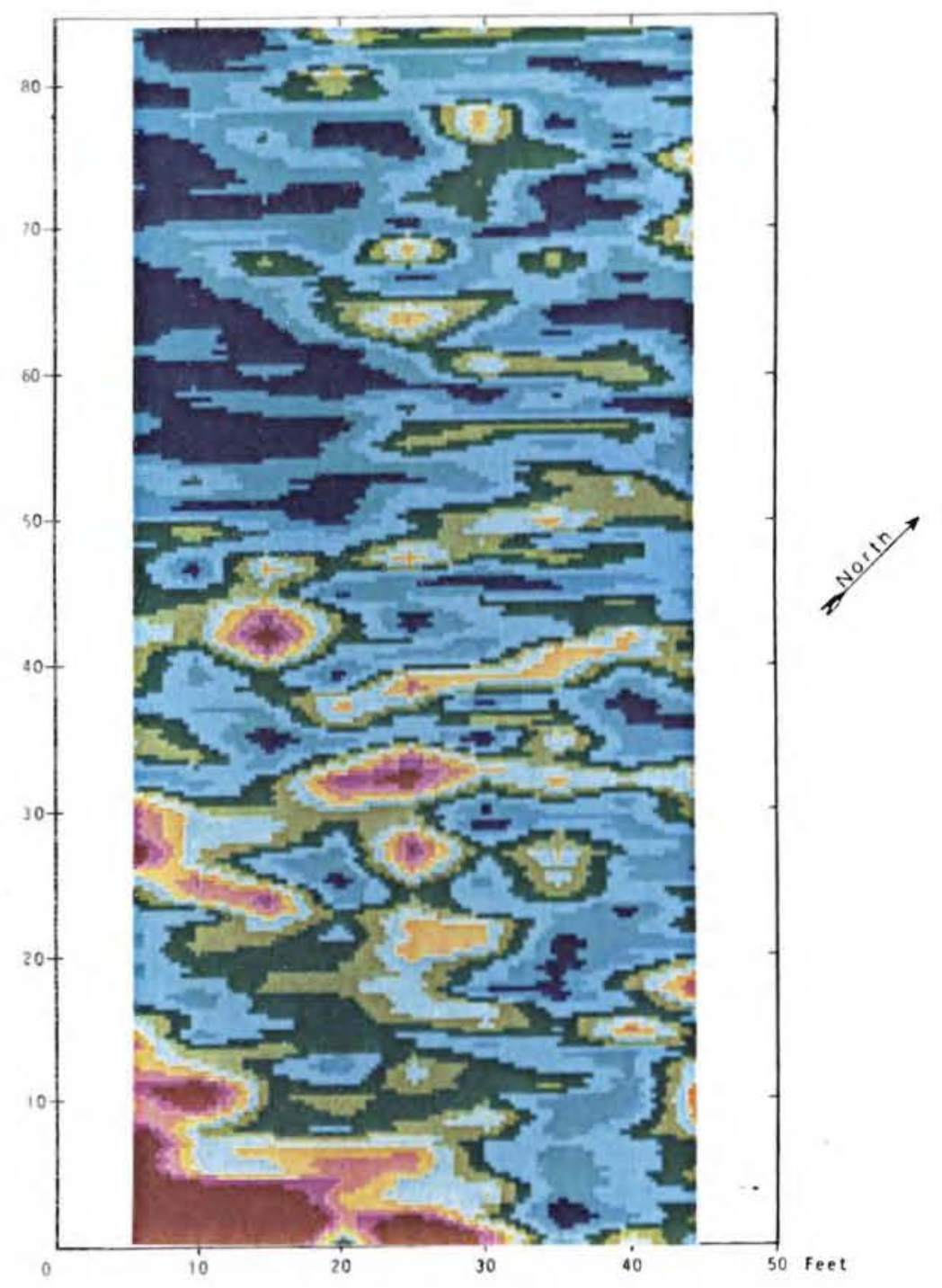

FIGURE 30. Level Sliced Color Map View of Radar Data from Area B, Site 3 . 


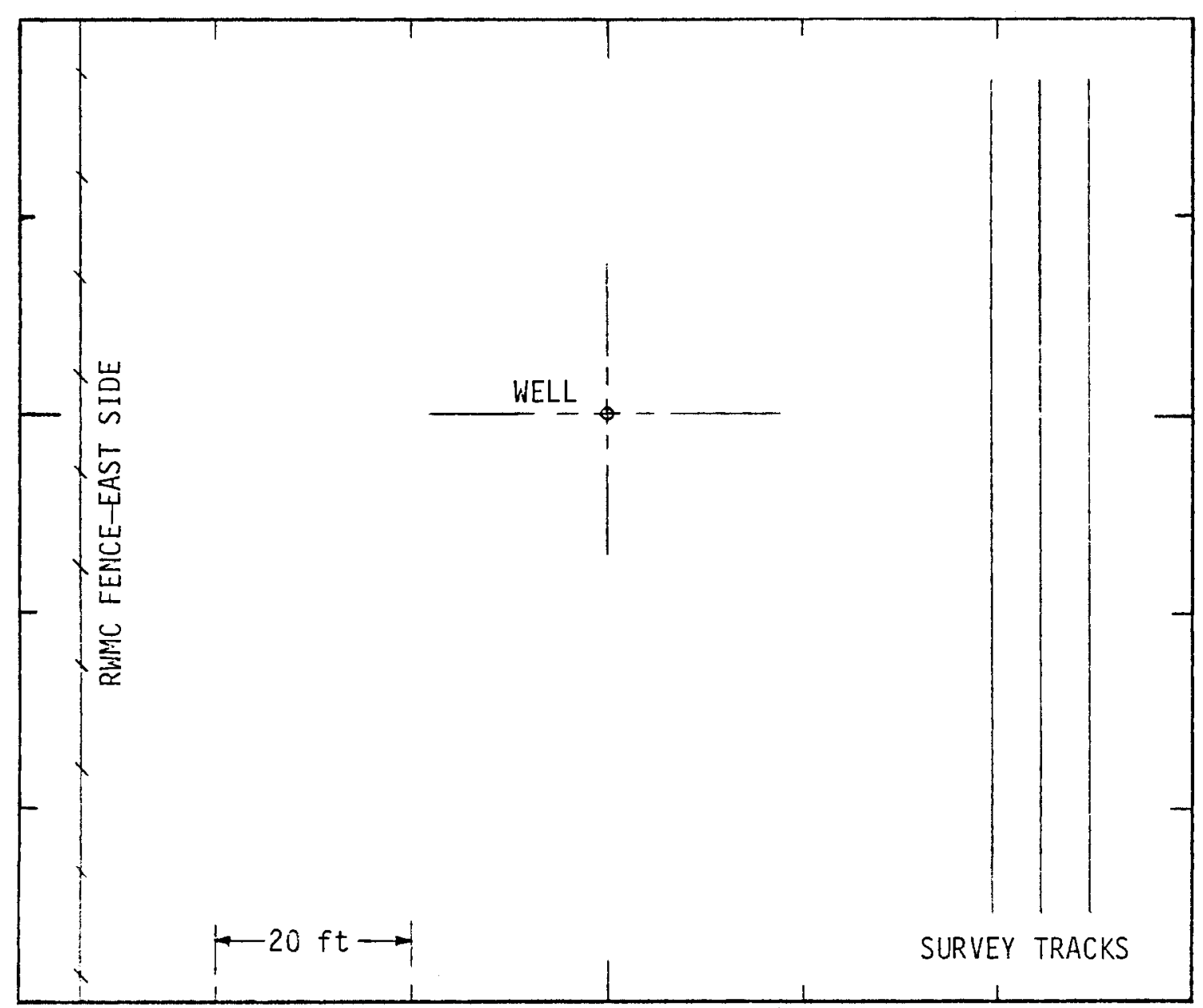

FIGURE 31. Test Site Location for Detection of Basalt Bedrock. The Three Survey Tracks Have a North-South Orientation and are $85 \mathrm{ft}$ Long. 


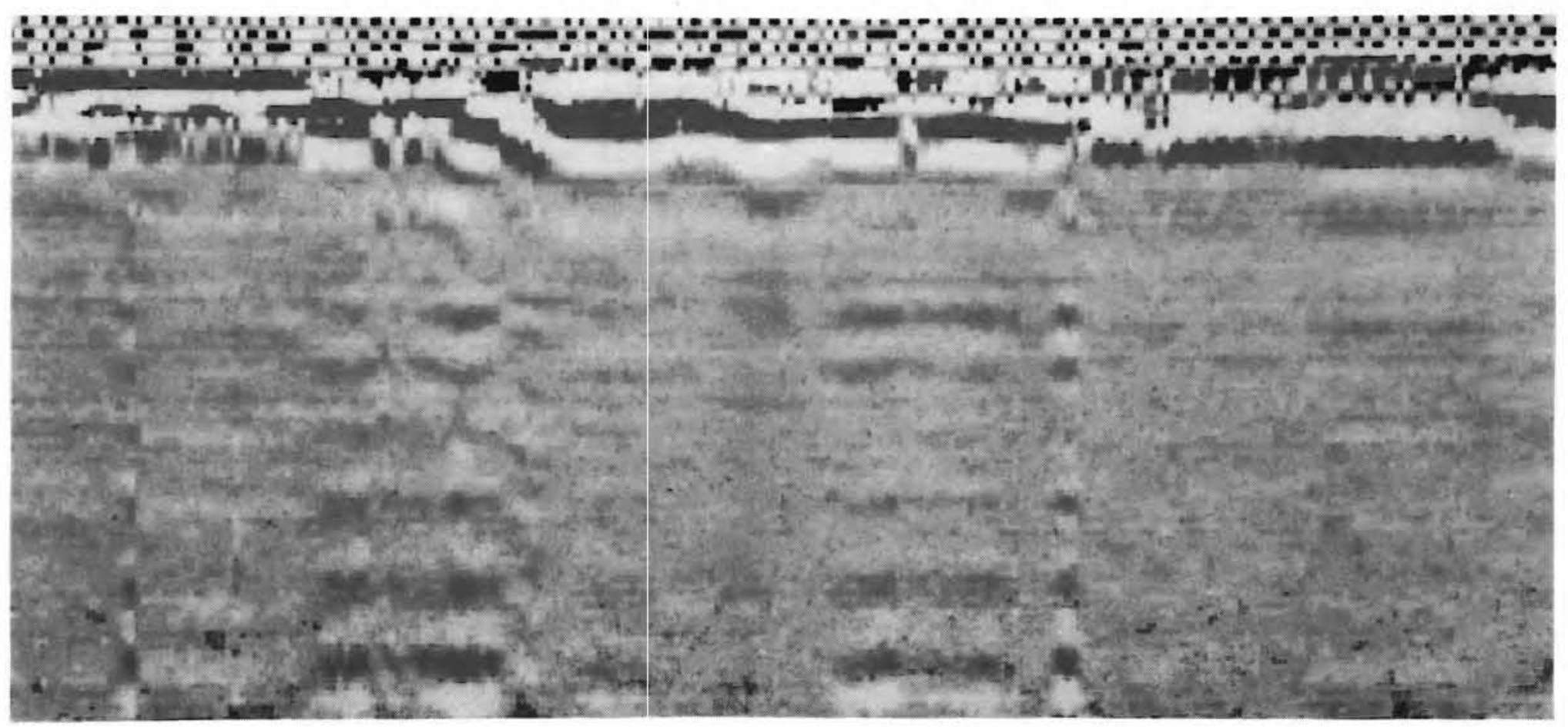

FIGURE 32. Radar Profile from Site 4. Ping Length is $156 \mathrm{nsec}$. 


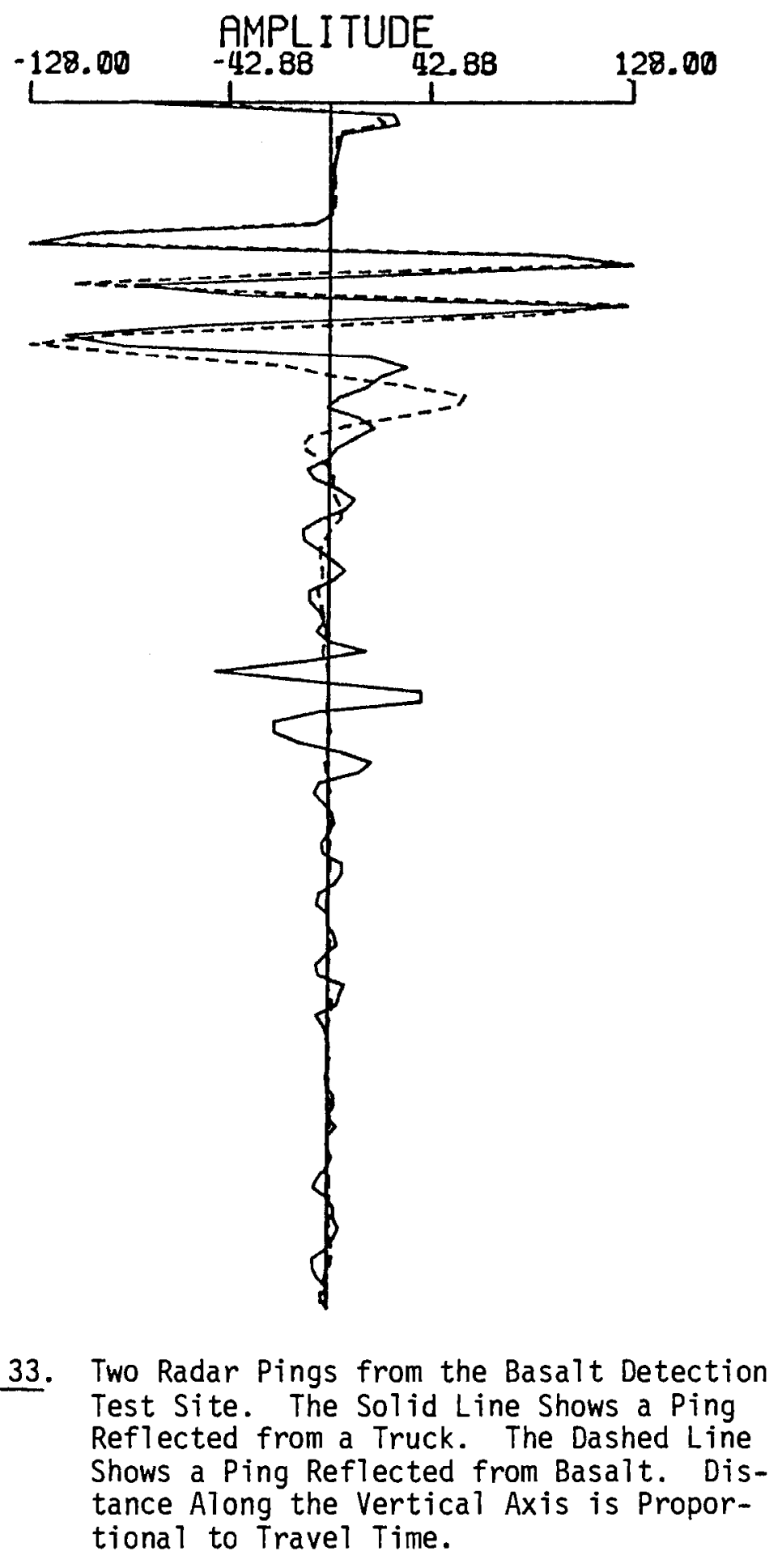


two radar pings. One (solid line) was reflected from the side of our computer truck which was located $30 \mathrm{ft}(9.1 \mathrm{~m})$ from the radar antenna. The other (dashed line) is a signal reflected from the subsurface. The truck reflection is obvious at approximately $40 \%$ of the total travel time. This gives a ping length of $156 \mathrm{nsec}$ and scaling factors of $16.6 \mathrm{nsec} / \mathrm{cm}$ and $11.2 \mathrm{nsec} / \mathrm{cm}$ for Figures 32 and 33, respectively. In Figure 33, the largest oscillations consist mainly of the waveform of the outgoing signal. It is derived from electrical feed-through in the radar transceiver and from a reflection from the ground surface approximately $4 \mathrm{~cm}$ below the antenna. Superimposed on the transmitted waveform is a similar, but smaller, signal reflected from the basalt. In Figure 33, the difference between the dashed line and the solid line can be attributed to the waveform component reflected from the basalt. In Figure 32, the transmitted waveform has been partially removed from the data. This was done by program REMVH. A rough reflecting interface is clearly present approximately $.8 \mathrm{~cm}$ below the top edge of the image or approximately $13 \mathrm{nsec}$ after the beginning of the transmitted signal. Using a travel time of $13 \mathrm{nsec}$ and a propagation velocity of $1.5\left(10^{8}\right) \mathrm{m} / \mathrm{sec}$ (see Section 5.2 ), we obtain a depth of $.98 \mathrm{~m}$ for the basalt surface. This is very close to the $1.0 \mathrm{~m}$ depth to basalt recorded in the well $\mathrm{log}$.

The propagation velocity of the radar signal in the ground is a function of the dielectric constant of the soil. The expression is

$$
v=\frac{c}{\sqrt{k}}
$$

where $V$ is the speed of propagation in the ground,

$C=3.0\left(10^{8}\right) \mathrm{m} / \mathrm{sec}$, the speed of propagation in free space, and

$K=$ the relative dielectric constant of the soil.

Our value for $V, 1.5\left(10^{8}\right) \mathrm{m} / \mathrm{sec}$, corresponds to a value of 4.0 for the relative dielectric constant. This is equal to the value for dry sand (4-6) and is probably reasonable for the dry RWMC soil. 


\subsection{REFERENCES}

1. J.W. Grace, R.D. Meininger, and P.M. Evans, "Impulse Radar System, Report of Conceptual Phase Investigation at the RWMC," EG\&G Idaho, Inc., Report No. RE-I-78-003, October, 1978.

2. "Evaluation of Methods for Subsurface Exploration at the RWMC," EG\&G Idaho, Inc., Report No. PR-W-78-011, 1978.

3. G.A. Sandness, "Characterization of the Hanford 300 Area Burial Grounds, Task 1 - Geophysical Evaluation," PNL Report No. PNL-2957 (In preparation).

4. M.B. Dobrin, Introduction to Geophysical Prospecting. 2nd Ed., McGrawHill Book Company, Inc., New York, 1960.

5. J.R. Heirtzler, G. Peter, M. Talwani, and E.G. Zurflueh, Magnetic Anomalies Caused by Two-Dimensional Structure: Their Computation by Digital Computers and Their Interpretation. Lamont Geological observatory Technical Report No. 6, CU-6-62 Nonr-Geology, 1962.

6. M. Talwani, "Computation with the Help of a Digital Computer of Magnetic Anomalies Caused by Bodies of Arbitrary Shape," Geophysics. 30:797-817 (1965).

7. D. Plouff, Derivation of Formulas and Fortran Programs to Compute Magnetic Anomalies of Prisms. U.S. Geological Survey Report No. USGS-GD-75-014 (1975).

8. M.J. Aitken, Physics and Archeology. Interscience Publishers, Inc., New York, 1961 .

9. J.C. Cook, "Radar Transparencies of Mine and Tunnel Rocks," Geophysics. 40:865-885 (1975).

10. R.M. Morey and W.S. Harrington, Jr. Feasibility Study of Electromagnetic Subsurface Profiling. U.S. Environmental Protection Agency Report No. EPA-R2-72-082, 1972.

11. D.C. Gates and R.A. Armistead. The Use of Advanced Technologies for Locating Underground Obstacles. Electric Power Research Institute Report No. 78-20-0, 1974.

12. L.A. Rubin, J.N. Griffin, and W.L. Sti11, Surface Site Investigation by Electromagnetic Radar, Phase 1 - Feasibility. National Science Foundation Report No. NSF/RA-76-0187 (1976).

13. J.F. Claerbout, Fundamentals of Geophysical Data Processing. McGrawHi11 Book Company, New York, NY (1976). 
14. B.K. Bhattacharyya, "Two-Dimensional Harmonic Analysis as a Tool for Magnetic Interpretation," Geophysics. 30:829-857, 1965. 
DISTRIBUTION

No. of

Copies

OFFSITE

25 EG\&G Idaho

P.0. Box 1625

Idaho Falls, ID 83401

WCBE2

J. D. Bishoff

A. A. Churm

DOE Chicago Patent Group

9800 South Cass Ave.

Argonne, IL 60439

27 DOE Technical Information Center

G. W. Cunningham

DOE Division of Waste

Management Production and

Reprocessing

Washington, DC 20545

C. R. Cooley

DOE Division of Waste

Management

Washington, DC 20545

G. H. Dajly

Division of Waste

Management Production and Processing

Washington, DC 20545

J. E. Dieckhoner

Division of Waste

Management Production

and Reprocessing

Washington, DC 20545

C. H. George

DOE Office of Assistant

Secretary for Energy

Technology

Washington, DC 20545
No. of

Copies

\author{
D. R. Spurgeon \\ DOE Office of Assistant \\ Secretary for Energy \\ Technology \\ Washington, DC 20545 \\ L. Dressin \\ DOE Office of Assistant \\ Secretary for Energy \\ Technology \\ Washington, DC 20545 \\ G. K. Ortel \\ DOE Office of Assistant \\ Secretary for Energy \\ Technology \\ Washington, DC 20545
}

A. F. Kluk

Division of Environmental Control Engineering

Nuclear Programs

Washington, DC 20545

W. E. Mott

Division of Environmental Control Engineering Washington, DC 20545

C. A. Heath

DOE Division of Waste Management Washington, DC 20545

S. Myers

DOE Office of Nuclear Waste Management

Washington, DC 20545

R. W. Ramsey

Division of Environmental Control Engineering Washington, DC 20545 
No. of

Copies

L. C. Braisley

DOE Office of the Assistant

Secretary of the Environment Washington, DC 20545

W. A. Brobst

Environmental Control

Engineering

Environmental Control

Technology

Washington, DC 20545

Department of Energy

Albuquerque Operations office

Albuquerque, NM 87115

Department of Energy

Argonne National Laboratory

Argonne, IL 60439

Department of Energy

Brookhaven National Laboratory

Upton, NY 11973

Department of Energy

Idaho Operations Office

Idaho Falls, ID 83401

Department of Energy

Nevada Operations Office

Las Vegas, NE 89114

Department of Energy

Oak Ridge Operations Office

Oak Ridge, TN 37830

Department of Energy

Oak Ridge National Laboratory

Oak Ridge, TN 37830

Department of Energy

Savannah River Operations office

Aiken, SC 29081
No. of

Copies

\author{
Department of Energy \\ Savannah River National \\ Laboratory \\ Aiken, SC 29081 \\ Department of Energy \\ Los Alamos National Laboratory \\ Los Alamos, NM 87545 \\ P. Columbo \\ Brookhaven National Laboratory \\ Upton, NY 11973 \\ E. L. Albenesius \\ Savannah River Nationa] \\ Laboratory \\ Aiken, SC 29081 \\ J. G. Steger \\ Los Alamos Scientific \\ Laboratory \\ Los Alamos, NM 87545 \\ L. J. Johnson \\ Los Alamos Scientific \\ Laboratory \\ Los Alamos, NM 87545 \\ T. Tamura \\ Oak Ridge NAtional Laboratory \\ Oak Ridge, TN 37830 \\ F. A. Morris \\ HARC \\ 4000 N.E. 41 st Street \\ P.0. Box 5395 \\ Seattle, WA 98105 \\ Atomic Industrial Forum, Inc. \\ 7101 Wisconsin Ave. \\ Washington, DC 20014 \\ Beverly Rawles \\ Battelle Memorial Institute \\ Office of Nuclear Waste \\ Isolation \\ 505 King Ave. \\ Columbus, $\mathrm{OH} 43201$
}


No. of

Copies

Environmental Protection Agency

Technology Assessment Division

Office of Radiation Programs

Washington, DC 20460

National Academy of Sciences

Radioactive Waste Management Committee

National Research Council

2101 Constitution Ave.

Washington, DC 20418

Nuclear Regulatory Commission

Division of Safeguards, Fuel

Cycle and Environmental

Research

Washington, DC 20545

C. Bishop

NRC Division of Fuel Cycle

Low Level Branch

Washington, DC 20555

Mail Stop 396-SS

C. Bishop

Division of Fuel Cycle

Low Level Branch

Washington, DC 20555

Mail Stop 396-SS

FOREIGN

International Atomic Energy Agency

Kartner Ring II

P.0. Box 590

A-1011 Vienna,

AUSTRIA

\section{ONSITE}

9 Richland Operations Office
R. E. Austin
0 . J. Elgert
R. E. Gerton

No. of

Copies
R. B. Goranson
J. L. Landon
H. E. Ransom
J. L. Rhodes
F. R. Standerfer
J. D. White

2 United Nuclear Industries

T. E. Dabrowski

J. F. Nemec

2 Rockwell Hanford Operations

J. L. Deichman

A. W. Graves

48 Pacific Northwest Laboratory

W. J. Bair

J. B. Brown

D. B. Cearlock

G. W. Dawson

J. R. Kimbrough

L. M. Martucci

S. J. Phillips

A. M. Platt

J. L. Rising

G. A. Sandness (20)

W. R. Wiley

Technical Information (5)

Publishing Coordination (2)

Water and Land Resources

Library (10) 
, 